\title{
Insights into the Active Site of Coproheme Decarboxylase from Listeria monocytogenes
}

\author{
Lisa Milazzo, ${ }^{\ddagger}$ Stefan Hofbauer, ${ }^{\dagger}$ Barry D. Howes, ${ }^{\ddagger}$ Thomas Gabler, ${ }^{\dagger}$ Paul G. Furtmüller, ${ }^{\dagger}$ \\ Christian Obinger, ${ }^{\dagger}{ }^{\dagger}$ and Giulietta Smulevich*, ${ }^{*} \neq 0$ \\ ${ }^{\ddagger}$ Dipartimento di Chimica “Ugo Schiff”, Università di Firenze, Via della Lastruccia 3-13, 50019 Sesto Fiorentino (Fi), Italy \\ ${ }^{\dagger}$ Department of Chemistry, Division of Biochemistry, BOKU - University of Natural Resources and Life Sciences, Muthgasse 18, \\ A-1190 Vienna, Austria
}

Supporting Information

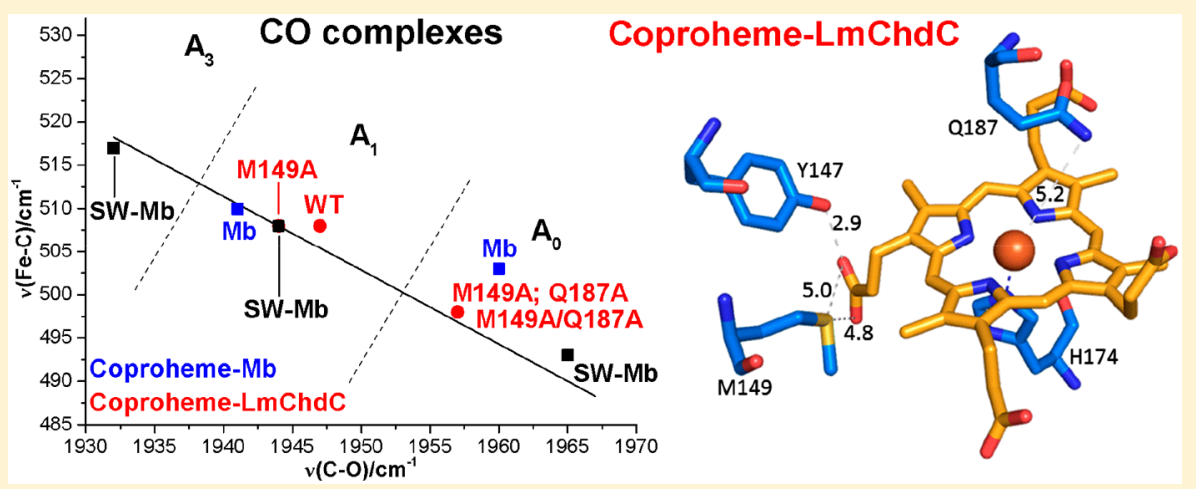

ABSTRACT: Coproheme decarboxylases (ChdC) catalyze the hydrogen peroxide-mediated conversion of coproheme to heme $b$. This work compares the structure and function of wild-type (WT) coproheme decarboxylase from Listeria monocytogenes and its M149A, Q187A, and M149A/Q187A mutants. The UV-vis, resonance Raman, and electron paramagnetic resonance spectroscopies clearly show that the ferric form of the WT protein is a pentacoordinate quantum mechanically mixed-spin state, which is very unusual in biological systems. Exchange of the Met149 residue to Ala dramatically alters the heme coordination, which becomes a 6-coordinate low spin species with the amide nitrogen atom of the Q187 residue bound to the heme iron. The interaction between M149 and propionyl 2 is found to play an important role in keeping the Q187 residue correctly positioned for closure of the distal cavity. This is confirmed by the observation that in the M149A variant two CO conformers are present corresponding to open $\left(\mathrm{A}_{0}\right)$ and closed $\left(\mathrm{A}_{1}\right)$ conformations. The $\mathrm{CO}$ of the latter species, the only conformer observed in the WT protein, is $\mathrm{H}$-bonded to Q187. In the absence of the Q187 residue or in the adducts of all the heme $b$ forms of ChdC investigated herein (containing vinyls in positions 2 and 4), only the $A_{0}$ conformer has been found. Moreover, M149 is shown to be involved in the formation of a covalent bond with a vinyl substituent of heme $b$ at excess of hydrogen peroxide.

oproheme decarboxylase (ChdC, formerly HemQ) is a key element in the coproporphyrin-dependent heme biosynthetic pathway of mainly monoderm, but also some diderm, archaea, and intermediate bacteria. ${ }^{1-5}$ In fact, it catalyzes the decarboxylation of the two propionate groups at positions 2 and 4 of iron-coproporphyrin III (coproheme) to form heme $b$. Many recent publications have elucidated the physiological role of $\mathrm{ChdC}, 3,6,7$ but its structure-function relationship is still not completely understood.

The interaction of apo-ChdC with coproheme has been recently investigated by means of spectroscopic techniques for both Listeria monocytogenes $(\mathrm{Lm})^{8-10}$ and Staphylococcus aureus (Sa).$^{11-13}$ Moreover, the crystal structures of the homopentameric coproheme-ChdC from Listeria monocytogenes (coproheme-LmChdC) at $1.69 \AA$ resolution (5LOQ) ${ }^{9}$ and of Geobacillus stearothermophilus (Gs) ChdC with manganesecoproporphyrin III at $1.8 \AA$ resolution $(5 \mathrm{~T} 2 \mathrm{~K})^{12}$ have been published. Both structures show that the coproheme iron of ChdC is weakly bound by a proximal histidine (H174 in Lm). On the distal side, no water molecules are coordinated to the iron atom, suggesting the presence of a 5-coordinated iron ${ }^{9}$ in agreement with the resonance Raman (RR) spectra. ${ }^{9,11}$ The distal Gln residue (Q187 in $\mathrm{Lm}$ ), conserved in Firmicutes ChdC, has been shown to be particularly important in the stabilization of the distal side since it interacts with incoming exogenous ligands, such as CO. ${ }^{12}$ This residue is involved in a $\mathrm{H}$-bond network with an Arg residue (R133 in Lm, R131 in $\mathrm{Sa})$, propionate 6 , and a water molecule. ${ }^{12}$ Furthermore, it controls together with a second Arg side chain (R179 in Lm) the substrate access channel of the active site. ${ }^{9}$ The two

Received: February 15, 2018

Revised: March 5, 2018

Published: March 14, 2018 
available structures of ChdC coproporphyrin III complexes show differences in the orientation of the cofactor. In the GsChdC manganese-coproporphyrin III complex unreactive propionates $\mathrm{p} 6$ and $\mathrm{p} 7$ are solvent exposed, ${ }^{12}$ whereas in the LmChdC iron-coproporphyrin III complex reactive $\mathrm{p} 2$ and unreactive p7 are facing the solvent. ${ }^{9}$ Clearly, this issue is critically important for the discussion of this reaction. After thorough examination of the electron densities in the respective structures (5LOQ and 5T2K) and unpublished additional experiments on $\mathrm{LmChdC}$, we have re-evaluated our analysis and now believe that the more appropriate interpretation of the structural data is that presented in the structure of GsChdC $(5 \mathrm{~T} 2 \mathrm{~K}) .^{12}$

In the present paper, we compare the structure and function of wild-type (WT) coproheme-LmChdC (hereafter indicated as coproheme-WT) and its M149A, Q187A, and M149A/Q187A mutants. It should be noted that M149 interacts with p2 $(5 \mathrm{~T} 2 \mathrm{~K})$ and not, as previously erroneously reported, with $\mathrm{p} 4$ (5LOQ). ${ }^{9}$ All the data are compared with those obtained for a reference protein, horse heart $(\mathrm{HH}) \mathrm{Mb}(\mathrm{HHMb}$, hereafter $\mathrm{Mb})$, reconstituted with coproheme.

The UV-vis, RR, and EPR data presented herein clearly show that the ferric form of the WT protein is a pentacoordinate quantum mechanically mixed-spin (5cQS). The QS state reflects a quantum mechanical admixture of intermediate $(S=3 / 2)$ and high $(S=5 / 2)$ spin states and is very unusual in biological systems. It has been found to be a distinctive characteristic of ferric cytochromes $c^{\prime},{ }^{14}$ model complexes, and Family 3 of the peroxidase-catalase superfamily. ${ }^{15-17}$ However, the structural origin and functional significance of the QS states remains elusive. Interestingly, exchange of the Met149 by Ala dramatically alters the heme coordination, since only a minor species analogous to the $5 \mathrm{cQS}$ observed for the WT remains, while the main species corresponds to a 6-coordinate (6c) LS species with the $\mathrm{N}$ atom of the Q187 residue being bound to the heme iron. Intriguingly, the activity of the mutant remains similar to that of the WT.

Moreover, in this work, we identify M149 as the amino acid that cross-links with the product heme $b$. In fact, we have previously reported that upon reaction with $\mathrm{H}_{2} \mathrm{O}_{2}$, coproheme is converted by ChdC to heme $b$ via a three-propionate intermediate (monovinyl, monopropionate deuteroheme) and, finally, at excess hydrogen peroxide becomes cross-linked to the protein moiety. $^{9}$

\section{EXPERIMENTAL PROCEDURES}

Generation of LmChdC Variants. Site-directed mutagenesis was performed to obtain the LmChdC M149A, Q187A, and M149A/Q187A variants using the QuikChange Lightning Kit (Agilent Technologies). The plasmid (pETM11) encoding the $\mathrm{N}$-terminal TEV-cleavable $6 \times$ His tagged fusion protein of LmChdC wild-type (ORF annotated as 1 mo2113 in the EGD-e genome, accession no. NC003210) was used as template for the single mutants, the template for the double mutant was the plasmid encoding LmChdC M149A. To exchange the methionine (atg) at position 149 to alanine ( $\mathrm{gcg}$, underlined) the following primers were used: $5^{\prime}$-gcctaaaaagcatatttgtttctacccagcgagtaaaaaaagggatggc- $3^{\prime}$ and $5^{\prime}$-gccatcccttttttactcgctgggtagaaacaaatatgctttttaggc- $3^{\prime}$. To exchange the glutamine (caa) at position 187 to alanine (gcg, underlined) the following primers were used: $5^{\prime}$-gaagctatgctggcaaagtacaagcgatcattggtggctccattg- $3^{\prime}$ and 5 -caatggagccaccaatgatcgctt gtactttgccagcata- gcttc-3'. Total volume of mutagenesis PCR was $20 \mu \mathrm{L}$. The PCR products were digested with dpnI and transformed into $E$. coli XL Gold cells. Cells were cultivated overnight at $37^{\circ} \mathrm{C}$ and plasmid DNA, carrying LmChdC M149A, Q187A, and M149A/Q187A variants, was extracted using the Monarch Plasmid Mini Prep Kit (New England BioLabs Inc.) and sent for sequencing.

Expression and Purification of LmChdC Wild-Type and Variants. WT and variants were subcloned into a modified version of the pET21(+) expression vector with an $\mathrm{N}$ terminal StrepII-tag, cleavable TEV protease, or into a pETM11 expression vector with an $\mathrm{N}$-terminal, TEV cleavable $6 \times \mathrm{His}$-tag, expressed in E. coli Tuner (DE3) cells (Merck/Novagen) and purified via a StrepTrap HP or a HisTrap HP $5 \mathrm{~mL}$ column (GE Healthcare). The respective tag was cleaved off and the pure protein was obtained after a preparative size exclusion chromatography step (HiLoad 16/60 Superdex 200 pg; GE Healthcare), as described in detail previously. ${ }^{8}$ The comparison of coproheme-WT and M149A obtained with and without HisTag (Figure S1) shows that while WT is not affected by the purification technique, the mutant is more sensitive. In particular, qualitatively the protein gives rise to the same mixture of coordination and spin states (see below), but the amount of $6 \mathrm{cLS}$ increases in the protein purified using the HisTag. However, the heme $b$ proteins, obtained upon addition of $\mathrm{H}_{2} \mathrm{O}_{2}$ to the coproheme complexes, are the same using a protein purified with or without His-Tag (data not shown).

Sample Preparation. Apo-Mb (horse heart, Sigma) was prepared using a modified extraction method by Teale, as described previously. ${ }^{8,18,19}$ Ferric coproheme was purchased from Frontier Scientific, Inc. (Logan, Utah, USA) as lyophilized powder. A coproheme solution at $\mathrm{pH} 7.0$ in $50 \mathrm{mM}$ Hepes buffer was prepared by dissolving the coproheme powder in a $0.5 \mathrm{M} \mathrm{NaOH}$ solution. A small concentrated aliquot of this solution was then mixed with an appropriate volume of $50 \mathrm{mM}$ Hepes buffer, $\mathrm{pH}$ 7.0.

All the protein-coproheme complexes were prepared by adding the coproheme solution at $\mathrm{pH} 7.0$ to the apo-proteins dissolved in $50 \mathrm{mM}$ Hepes buffer, $\mathrm{pH}$ 7.0. The ferric heme $b$ LmChdC complexes of WT and variants were prepared by adding small aliquots of a concentrated solution of $\mathrm{H}_{2} \mathrm{O}_{2}$ in 50 $\mathrm{mM}$ Hepes buffer, $\mathrm{pH}$ 7.0, to the corresponding coprohemeLmChdC complex. The imidazole complexes of coproheme$\mathrm{WT}$ and coproheme-Mb were prepared by adding small aliquots of a $0.1 \mathrm{M}$ imidazole solution in $50 \mathrm{mM}$ Hepes buffer at $\mathrm{pH} 7.0$ to coproheme-WT and coproheme-Mb solutions until no further UV-vis spectral changes were observed.

The $\mathrm{Fe}(\mathrm{II})-\mathrm{CO}$ adducts at $\mathrm{pH} 7.0$ were prepared by flushing the ferric coproheme/heme $b$ complexes with ${ }^{12} \mathrm{CO}$ or ${ }^{13} \mathrm{CO}$ (Rivoira, Milan, Italy), and then reducing the coproheme/heme $b$ by addition of a freshly prepared sodium dithionite solution $\left(20 \mathrm{mg} \mathrm{mL}^{-1}\right)$.

Sample concentrations, in the range of $15-100 \mu \mathrm{M}$ for UVvis and RR measurements, were determined using an extinction coefficient $(\varepsilon)$ of $128800 \mathrm{M}^{-1} \mathrm{~cm}^{-1}$ at $390 \mathrm{~nm}$ (coproheme); ${ }^{9}$ $68000 \mathrm{M}^{-1} \mathrm{~cm}^{-1}$ at $395 \mathrm{~nm}$ (coproheme-WT and variants); ${ }^{10}$ $85800 \mathrm{M}^{-1} \mathrm{~cm}^{-1}$ at $391 \mathrm{~nm}$ (coproheme-Mb); $76600 \mathrm{M}^{-1}$ $\mathrm{cm}^{-1}$ at $410 \mathrm{~nm}$ (heme $b$-LmChdC WT and variants). ${ }^{10}$

Electronic Absorption. Electronic absorption spectra were recorded using a $5 \mathrm{~mm} \mathrm{NMR} \mathrm{tube} \mathrm{(300} \mathrm{nm} \mathrm{min}^{-1}$ scan rate) or a $1 \mathrm{~mm}$ cuvette $\left(600 \mathrm{~nm} \mathrm{~min}{ }^{-1}\right.$ scan rate $)$ at $25^{\circ} \mathrm{C}$ by means of a Cary 60 spectrophotometer (Agilent Technologies) with a resolution of $1.5 \mathrm{~nm}$. Absorption spectra were measured both 
prior to and after $\mathrm{RR}$ measurements to ensure that no degradation occurred under the experimental conditions used. For the differentiation process, the Savitzky-Golay method was applied using 15 data points (LabCalc, Galactic Industries, Salem, NH). No changes in the wavelength or in the bandwidth were observed when the number of points was increased or decreased.

Resonance Raman (RR). The resonance Raman (RR) spectra were obtained at $25{ }^{\circ} \mathrm{C}$ using a $5 \mathrm{~mm}$ NMR tube by excitation with the 356.4 and $406.7 \mathrm{~nm}$ lines of a $\mathrm{Kr}^{+}$laser (Coherent, Innova300 C, Coherent, Santa Clara, CA, USA). Backscattered light from a slowly rotating NMR tube was collected and focused into a triple spectrometer (consisting of two Acton Research SpectraPro 2300i instruments and a SpectraPro 2500i instrument in the final stage with gratings of 3600 grooves $/ \mathrm{mm}$ and 1800 grooves $/ \mathrm{mm}$ ) working in the subtractive mode, equipped with a liquid nitrogen-cooled CCD detector. A cylindrical lens was used to focus the laser beam on the coproheme-Mb-CO adducts.

For the low temperature experiments, a $50 \mu \mathrm{L}$ drop of the sample was put in a $1.5-\mathrm{cm}$-diameter quartz crucible that was positioned in a THMS600 cryostat (Linkam Scientific Instruments, Surrey, UK) and frozen. After freezing the sample, the cryostat was positioned vertically in front of the triple spectrometer and the laser light was directed onto the quartz window. To avoid sample denaturation, the laser position was changed frequently. The sample temperature was maintained at $80 \mathrm{~K}$.

A spectral resolution of $1.2 \mathrm{~cm}^{-1}$ and spectral dispersion of $0.40 \mathrm{~cm}^{-1} /$ pixel were calculated theoretically on the basis of the optical properties of the spectrometer for the 3600 grating; for the 1800 grating, used to collect the RR spectrum obtained at $\lambda_{\text {exc }} 406.7 \mathrm{~nm}$ of coproheme alone, the spectral resolution was 4 $\mathrm{cm}^{-1}$ and spectral dispersion $1.2 \mathrm{~cm}^{-1} /$ pixel. The RR spectra were calibrated with indene and carbon tetrachloride as standards to an accuracy of $1 \mathrm{~cm}^{-1}$ for intense isolated bands. All RR measurements were repeated several times under the same conditions to ensure reproducibility. To improve the signal-to-noise ratio, a number of spectra were accumulated and summed only if no spectral differences were noted. All spectra were baseline-corrected.

Electron Paramagnetic Resonance Spectroscopy (EPR). EPR was performed on a Bruker EMX continuous wave $(\mathrm{cw})$ spectrometer, operating at X-band $(9 \mathrm{GHz})$ frequencies. The instrument was equipped with a high sensitivity resonator and an Oxford Instruments ESR900 helium cryostat. Spectra were recorded under nonsaturating conditions using $2 \mathrm{~mW}$ microwave power, $100 \mathrm{kHz}$ modulation frequency, $1 \mathrm{mT}$ modulation amplitude, and $40 \mathrm{~ms}$ conversion time, $40 \mathrm{~ms}$ time constant, and 2048 points. Samples $(100 \mu \mathrm{L}$ of $100-300 \mu \mathrm{M})$ of recombinant WT, M149A variant and coproheme- $\mathrm{Mb}$ were prepared in $50 \mathrm{mM}$ Hepes buffer, $\mathrm{pH}$ 7.0, transferred into Wilmad quartz tubes ( $3 \mathrm{~mm}$ inner diameter), and flash frozen in liquid nitrogen. In order to remove $\mathrm{O}_{2}$, the tubes were flushed with argon while the sample was kept frozen on dry ice. The measurements were performed at $10 \mathrm{~K}$, after testing temperatures between 4 and $20 \mathrm{~K}$ to determine the optimum nonsaturating experimental conditions. The spectra were simulated with the Easyspin toolbox for Matlab ${ }^{20}$ using a weighted sum of simulations of the individual high-spin (HS) and low-spin (LS) species. The rhombicity was obtained from $g_{x}{ }^{\text {eff }}$ and $g_{y}{ }^{\text {eff }}$ and the relative intensities were calculated on the basis of the simulations, following the procedure of Aasa and
Vanngard to account for the different integral intensity per unit spin of species that display different effective $g$ values (as found in LS and HS centers). ${ }^{21,22}$

Enzymatic Activity of LmChdC Variants. Conversion to heme $b$ of the coproheme complexes of LmChdC M149A, Q187A, and M149A/Q187A was followed spectroscopically on a Hitachi U3900 spectrophotometer using a quartz cuvette in a thermostated cuvette-holder $\left(25^{\circ} \mathrm{C}\right)$ under constant stirring, analogous to the procedure used to determine the activity of the wild-type protein. ${ }^{9}$ Briefly, Michaelis-Menten parameters were determined using the initial linear phase of increase in absorbance at $410 \mathrm{~nm}\left(\varepsilon_{410}=76600 \mathrm{M}^{-1} \mathrm{~cm}^{-1}\right){ }^{10} 1 \mu \mathrm{M}$ coproheme complexes of the LmChdC mutants M149A, Q187A, and M149A/Q187A in $50 \mathrm{mM}$ phosphate buffer, $\mathrm{pH}$ 7.0, were used and the reactions were started by the addition of $20-200 \mu \mathrm{M} \mathrm{H}_{2} \mathrm{O}_{2}$ (Sigma); the concentrations were checked spectrophotometrically prior to each measurement $\left(\varepsilon_{240}=39.4\right.$ $\left.\mathrm{M}^{-1} \mathrm{~cm}^{-1}\right) .^{23}$ The production rates of heme $b\left(\mu \mathrm{M} \mathrm{s}^{-1}\right)$ were plotted against $\mathrm{H}_{2} \mathrm{O}_{2}$ concentrations and the $K_{\mathrm{M}}$ and $V_{\max }$ calculated using a Hanes plot [extraction of catalytic parameters from the slope $\left(1 / V_{\max }\right)$ and the intercept $\left.\left(K_{\mathrm{M}} / V_{\max }\right)\right]$.

Titrations to determine the reaction stoichiometry of $\mathrm{H}_{2} \mathrm{O}_{2}$ to coproheme catalyzed by the LmChdC mutants M149A, Q187A, and M149A/Q187A were performed and monitored spectrophotometrically and via mass spectrometry as described previously. ${ }^{9}$ Mass spectrometry was set up to detect small molecules (coproheme, heme $b$, and monovinyl, monopropionate deuteroheme) as well as the entire protein, to detect eventual protein modifications.

Binding of Coproheme to the LmChdC Variants. The kinetics of coproheme binding to the apo-LmChdC M149A, Q187A, and M149A/Q187A variants was measured using a stopped-flow apparatus equipped with a diode array detector (model SX-18MV, Applied Photophysics), in the conventional mode. The optical quartz cell with a path length of $10 \mathrm{~mm}$ had a volume of $20 \mu \mathrm{L}$. The fastest mixing time was $1 \mathrm{~ms}$. All measurements were performed at room temperature and in 50 $\mathrm{mM}$ phosphate buffer, $\mathrm{pH}$ 7.0. The concentration of coproheme in the cell was $1 \mu \mathrm{M}$ and ChdC was present in excess $(3.5 \mu \mathrm{M})$, to ensure pure spectral species of the coproheme bound proteins. The reactions were simulated and rates estimated using Pro-Kineticist software (Applied Photophysics).

\section{RESULTS}

Binding of Coproheme to LmChdC. Insertion of coproheme into the protein leading to the formation of the WT complex causes an overall red-shift of the UV-vis spectrum. The binding of coproheme to WT has been followed monitoring the UV-vis spectral variations and shows a biphasic behavior, with a very rapid first phase $\left(k_{\text {on }} \sim 1.5 \times 10^{8} \mathrm{M}^{-1} \mathrm{~s}^{-1}\right)$ and a slower second rearrangement phase $\left(k_{\text {rearr }} \sim 2 \times 10^{6} \mathrm{M}^{-1}\right.$ $\left.\mathrm{s}^{-1}\right) .{ }^{5,10}$ The kinetics of coproheme binding by apo-M149A is also biphasic (Figure S2) with similar apparent binding constants $\left(k_{\text {on }} \sim 1.6 \times 10^{8} \mathrm{M}^{-1} \mathrm{~s}^{-1} ; k_{\text {rearr }} \sim 9 \times 10^{6} \mathrm{M}^{-1}\right.$ $\mathrm{s}^{-1}$ ). When the distal glutamine (Q187) is exchanged by an alanine, coproheme binding $\left(k_{\text {on }}\right)$ is slowed down $\left(k_{\text {on }} \sim 9.4 \times\right.$ $\left.10^{7} \mathrm{M}^{-1} \mathrm{~s}^{-1} ; k_{\text {rearr }} \sim 2 \times 10^{6} \mathrm{M}^{-1} \mathrm{~s}^{-1}\right)$. In the LmChdC double mutant M149A/Q187A, the binding behavior is even more altered with estimated binding constants of $k_{\mathrm{on}} \sim 1.5 \times 10^{7} \mathrm{M}^{-1}$ $\mathrm{s}^{-1}$ and $k_{\text {rearr }} \sim 7.0 \times 10^{5} \mathrm{M}^{-1} \mathrm{~s}^{-1}$. The observed intermediate spectrum (representing the end of the first binding phase) also differs from the respective spectra observed in the WT and the 
other variants. The spectrum shows maxima similar to those found in free coproheme, although with lower extinction coefficients (Figure S2E).

Conversion of Coproheme to Heme b. A 2-fold stoichiometric excess of $\mathrm{H}_{2} \mathrm{O}_{2}$ mediates the conversion of the coproheme complex into heme $b$. Upon addition of excess hydrogen peroxide, the prosthetic group is modified and becomes covalently bound to the protein as demonstrated by mass spectrometric analysis (Figure 1). In fact, typically,

$31500 \quad 32000 \quad 32500 \quad 33000$

Figure 1. Cross-linking of heme $b$ to LmChdC mediated by excess hydrogen peroxide. Mass spectrometric analysis of the entire protein of LmChdC WT (apo-form 31977.2 Da; cross-linked $32590.5 \mathrm{Da}$, black) and LmChdC M149A (31 917.0 Da, red). The green line with its label shows the mass difference between apo-LmChd WT and holoLmChdC WT. The Coproheme-LmChdC complexes were titrated with $\mathrm{H}_{2} \mathrm{O}_{2}$ up to a 2-fold excess; subsequently, the mass spectroscopic measurements were performed on heme $b$-LmChdC WT and heme $b$ LmChdC M149A.

unmodified heme $b$ does not bind to the protein and is lost during sample preparation and measurement. However, at excess $\mathrm{H}_{2} \mathrm{O}_{2}$ a total mass of $32950.5 \mathrm{Da}$ was detected, which corresponds to the mass of LmChdC WT plus heme $b$ (Figure 1). ${ }^{9}$ By contrast, in LmChdC M149A the mass was $31917.0 \mathrm{Da}$ even after incubation with excess of hydrogen peroxide (Figure 1). This clearly identifies M149 as the site of covalent crosslinking. It is reasonable to assume that in the WT protein, excess $\mathrm{H}_{2} \mathrm{O}_{2}$ mediates the linkage between the vinyl substituent at position 2 of heme $b$ and M149 via a sulfonium ion bond as has been demonstrated for human myeloperoxidase. ${ }^{24-27}$

The decarboxylation of the propionate groups at positions 2 and 4 of coproheme leading to the formation of heme $b$ is a relatively slow process. ${ }^{2,9,11}$ Steady-state kinetic parameters and the determination of the stoichiometry of LmChdC WT were reported in a previous study. ${ }^{9}$ In WT and the mutant M149A full conversion of coproheme to heme $b$ requires the addition of two stoichiometric equivalents of hydrogen peroxide (Figure S3A,D). The activity of the M149A variant is characterized by an apparent $k_{\text {cat }} / K_{\mathrm{M}}$ value of $1.5 \times 10^{2} \mathrm{M}^{-1} \mathrm{~s}^{-1}$ (Figure S3E), which is only slightly lower than that for the WT $\left(1.8 \times 10^{2}\right.$ $\left.\mathrm{M}^{-1} \mathrm{~s}^{-1}\right)$. ${ }^{9}$ Interestingly, the $K_{\mathrm{M}}$ value for the M149A variant is approximately 4.7 -fold higher and the turnover number $\left(k_{\text {cat }}\right)$ is also increased 4-fold compared to the WT. This indicates impaired accessibility or binding of $\mathrm{H}_{2} \mathrm{O}_{2}$ for the variant, which agrees well with the increased amount of the 6cLS species as demonstrated below. Conversely, the stoichiometry of coproheme conversion to heme $b$ upon addition of hydrogen peroxide differs in the Q187A and M149A/Q187A variants. Approximately 3 equiv of hydrogen peroxide is needed to fully convert coproheme to heme $b$ (Figure S3B-D). Steady-state kinetic parameters for the Q187A mutant show that the $K_{\mathrm{M}}$ value is 5.6-fold higher than for the WT, whereas the turnover number $\left(k_{\text {cat }}\right)$ is almost identical. ${ }^{9}$ Due to pronounced heme bleaching and precipitation upon addition of hydrogen peroxide (Figure S3C), it was impossible to reliably determine the catalytic parameters for the double M149A/Q187A mutant.
The formation of the vinyl groups upon conversion of the coproheme complex into heme $b$ leads to an overall red-shift of the electronic absorption spectra compared to the coproheme complexes (Figure S4, panel A) and to the appearance of two $\nu(\mathrm{C}=\mathrm{C})$ vinyl stretching modes in the high frequency region of the RR spectrum at 1621 and $1632 \mathrm{~cm}^{-1}$ (Figure S4, panel B). A vinyl stretch frequency of $1632 \mathrm{~cm}^{-1}$ is quite high and indicates a fairly low degree of conjugation between the vinyl double bond and the porphyrin macrocycle. ${ }^{28}$ A lower degree of conjugation for one of the vinyl modes can explain the blue shift (by about 3-4 nm) of the Soret maximum of the heme $b$ LmChdC WT and mutant complexes compared to a $6 \mathrm{cLS}$ protein characterized by a heme group with both vinyl groups conjugated, as for the Mb-Im complex, which has a Soret maximum at $414 \mathrm{~nm}$ (data not shown) and both vinyl bands coincident at $1621 \mathrm{~cm}^{-1} .^{29}$ All the spectra are typical of a main 6cLS species (pink bands), characterized by a Soret band at 410-411 nm, visible bands at 533 and $568 \mathrm{~nm}$, and RR core size bands at $1503\left(\nu_{3}\right), 1580\left(\nu_{2}\right)$, and $1638\left(\nu_{10}\right) \mathrm{cm}^{-1}$. Interestingly, in the M149A mutant, the $\nu_{3}$ and $\nu_{2}$ bands are very broad, and the maxima are shifted toward higher frequencies with respect to those of the other proteins. This might be due to the presence of two different $6 \mathrm{cLS}$ forms, one corresponding to the form present in all proteins $\left(\nu_{3}\right.$ and $\nu_{2}$ bands at 1503 and $1580 \mathrm{~cm}^{-1}$, respectively) whose sixth ligand has not been identified, and the other with the Q187 as the sixth ligand $\left(\nu_{3}\right.$ and $\nu_{2}$ bands at 1507 and $1588 \mathrm{~cm}^{-1}$, respectively), as observed for the coproheme complex (see below).

In the spectra of the WT, Q187A, and M149A/Q187A proteins, even at very high $\mathrm{H}_{2} \mathrm{O}_{2}$ :protein molar ratios $(R>10)$, a residual 5cHS species remains, as suggested by the band at $396 \mathrm{~nm}$ observed in the second derivative UV spectra, and the $\nu_{3}$ and $\nu_{2}$ bands at 1491 and $1574 \mathrm{~cm}^{-1}$, respectively, in the RR spectra.

Interestingly, the spectroscopic studies of the ferric heme $b$ wild-type ChdC from M. tuberculosis ${ }^{1}$ and $S$. aureus ${ }^{11}$ indicate that the proteins are 5-coordinate (5c) high spin. Clearly, these results suggest that the heme cavity architecture of LmChdC is different.

Characterization of WT and Mutant Ferric Coproheme Containing Proteins. Figure 2 shows the UV-vis absorption spectra together with their second derivative spectra $\left(D^{2}\right)$ of coproheme and its complexes with $\mathrm{Mb}$, LmChdC, and its M149A mutant in which the conserved Met residue, which interacts with the propionate in position 2 , is replaced by the apolar Ala residue. Unlike heme $b$, that has two propionates and two vinyl groups, coproheme has 4 propionates and no vinyl groups. Consequently, due to the lack of vinyl conjugation, an overall blue-shift of the UV-vis spectrum with respect to heme $b$ proteins is predicted. ${ }^{28}$ Moreover, the $\nu_{2}$ core-size marker band in the RR spectrum is up-shifted by up to $12 \mathrm{~cm}^{-1} .30$

Visual inspection of the electronic absorption spectra shows that the coproheme molecule and the coproheme-LmChdC complex give rise to very similar spectra. The coproheme molecule is characteristic of a pure $5 \mathrm{cHS}$ species, with a Soret band at $390 \mathrm{~nm}$, visible bands at 492 and $530 \mathrm{~nm}$, and a CT1 band at $614 \mathrm{~nm}$ (Figure 2). The Soret band of the coprohemeLmChdC WT complex broadens with a maximum at $393 \mathrm{~nm}$ ( $396 \mathrm{~nm}$ in the $\mathrm{D}^{2}$ spectrum), and in the visible region, bands at 494 and $538 \mathrm{~nm}$ and a CT1 band at $630 \mathrm{~nm}$ are observed. ${ }^{9,10}$

The case of the M149A mutant is quite different. The UVvis spectrum of the coproheme-M149A variant is clearly a 


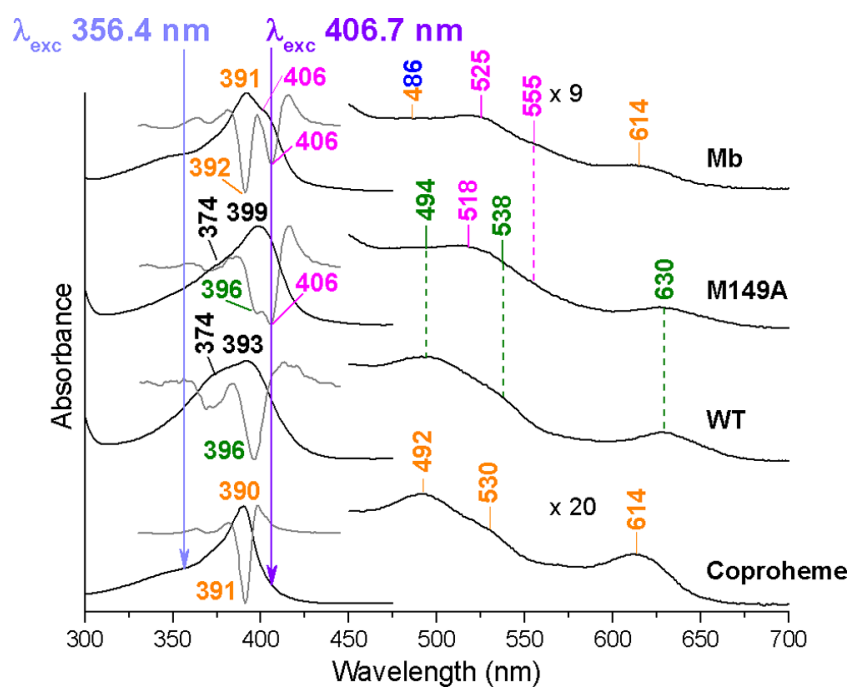

Figure 2. UV-vis absorption and second derivative $\left(\mathrm{D}^{2}\right)$ spectra of coproheme and the coproheme complexes with LmChdC WT, its M149A mutant, and Mb. The band wavelengths assigned to $5 \mathrm{cHS}$, $5 \mathrm{cQS}, 6 \mathrm{cHS}$, and $6 \mathrm{cLS}$ species are indicated in orange, olive green, blue, and magenta, respectively, (see text). The spectra have been shifted along the ordinate axis to allow better visualization. The 450$700 \mathrm{~nm}$ region of coproheme and the coproheme complexes spectra is expanded 20- and 9-fold, respectively. The excitation wavelengths used for the RR experiments are also shown in light violet (the $356.4 \mathrm{~nm}$ line) and in violet (the $406.7 \mathrm{~nm}$ line).

mixture of the species observed for the WT and another form, characterized by a Soret band at $406 \mathrm{~nm}, \mathrm{Q}$ bands at 518 and $555 \mathrm{~nm}$. A species analogous to the latter form is observed in the spectrum of the coproheme-Mb complex, which also shows two Soret bands, particularly evident in the second derivative spectrum, at 392 and $406 \mathrm{~nm}$.

Figure 3 shows the corresponding RR spectra taken with two excitation wavelengths (356.4 and $406.7 \mathrm{~nm}$ ). The UV-vis spectrum indicates that coproheme is characterized by a pure $5 \mathrm{cHS}$ state with core-size RR bands, observed for both excitation wavelengths, at $1493\left(\nu_{3}\right), 1585\left(\nu_{2}\right)$, and 1628 $\left(\nu_{10}\right) \mathrm{cm}^{-1}$. On the contrary, the RR spectra of the coprohemeWT complex, taken with excitation wavelengths at 356.4 and $406.7 \mathrm{~nm}$, i.e., on the blue and red sides of the Soret maximum, respectively, are very similar and clearly indicate the presence of two species. A minor species with core size marker bands at $1490\left(\nu_{3}\right), 1585\left(\nu_{2}\right)$, and $1628\left(\nu_{10}\right) \mathrm{cm}^{-1}$, analogous to the $5 \mathrm{cHS}$ form observed for pure coproheme, and a main species with core size marker bands at $1503\left(\nu_{3}\right), 1579\left(\nu_{2}\right)$, and 1635 $\left(\nu_{10}\right) \mathrm{cm}^{-1}$. The assignment of this latter form is not straightforward, since although the RR might correspond to a 6cLS species, there is no evidence for such a species in the UV-vis spectrum. In fact, the Soret band at $393 \mathrm{~nm}$ and CT band at $630 \mathrm{~nm}$ are consistent with a 5cHS species.

Unlike the WT, the RR spectra of the coproheme-M149A variant taken with the two excitation wavelengths are quite different. The spectrum obtained with the $356.4 \mathrm{~nm}$ laser line, in resonance with the Soret band at $396 \mathrm{~nm}$, is almost identical to that observed for the WT, in terms of both the band frequencies and intensities. In contrast, the most intense RR bands in the spectrum obtained with the $406.7 \mathrm{~nm}$ laser line, in resonance with the Soret band at $406 \mathrm{~nm}$, are at $1507\left(\nu_{3}\right)$, $1593\left(\nu_{2}\right)$, and $1640\left(\nu_{10}\right) \mathrm{cm}^{-1}$. This spectrum is assigned to a $6 \mathrm{cLS}$ heme. Interestingly, the spectrum very closely resembles that of the coproheme-Mb complex. Two Soret bands, particularly evident in the second derivative spectrum, at 392 and $406 \mathrm{~nm}$ are observed. The Soret at $406 \mathrm{~nm}$, Q bands at 525 and $555 \mathrm{~nm}$, and the RR bands at $1508\left(\nu_{3}\right), 1594\left(\nu_{2}\right)$, and

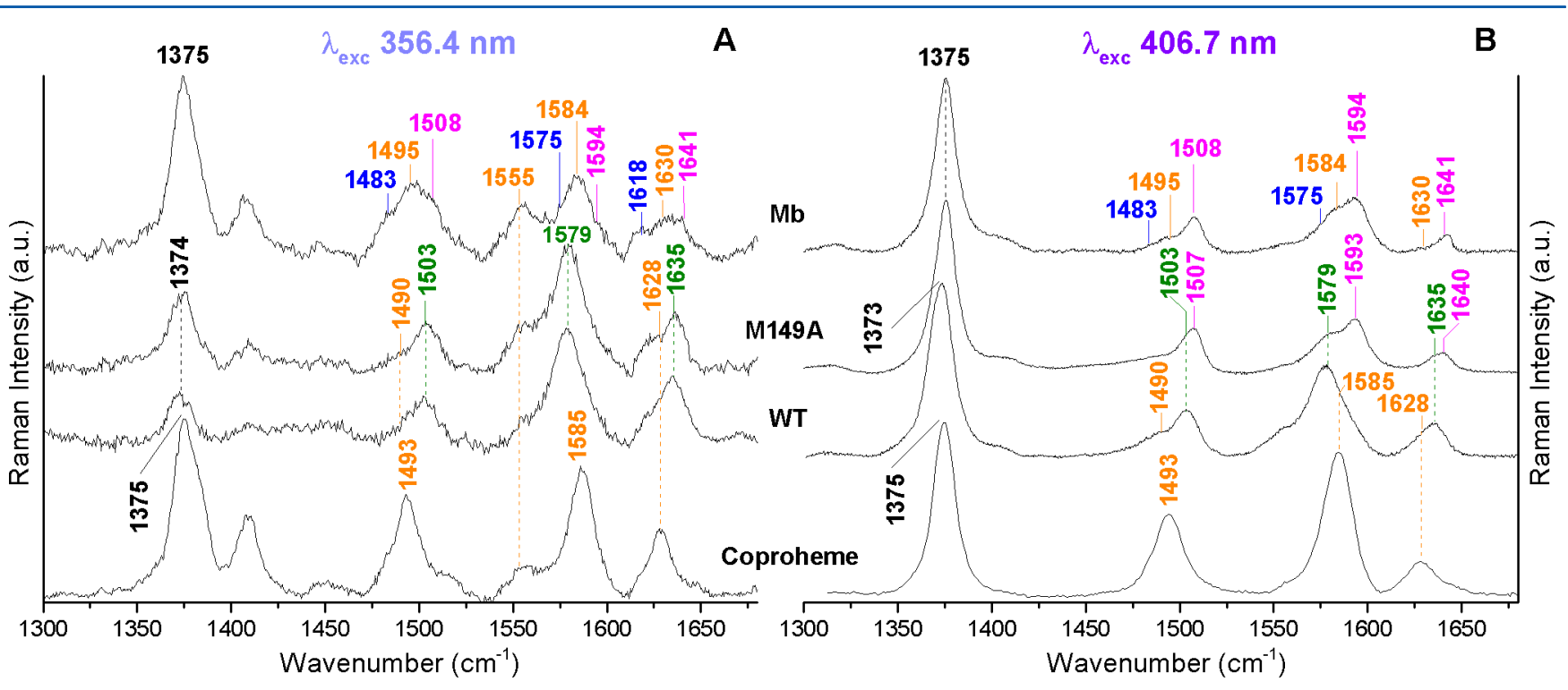

Figure 3. High frequency region RR spectra obtained at room temperature, with the 356.4 (Panel A) and $406.7 \mathrm{~nm}$ (Panel B) excitation wavelengths, of coproheme, and the coproheme complexes of LmChdC WT, its M149A mutant, and Mb. The band wavenumbers assigned to 5cHS, $5 \mathrm{cQS}, 6 \mathrm{cHS}$, and 6cLS species are indicated in orange, olive green, blue, and magenta, respectively (see text). The spectra have been shifted along the ordinate axis to allow better visualization. Experimental conditions: (A) laser power at the sample $5 \mathrm{~mW}$, average of 10 spectra with 120 min integration time (Coproheme); laser power at the sample $2 \mathrm{~mW}$; average of 7 spectra with 70 min integration time (WT), 8 spectra with 80 min integration time (M149A), and 24 spectra with 240 min integration time (Mb). (B) laser power at the sample $5 \mathrm{~mW}$; average of 2 spectra with 10 min integration time with 1800 grating (Coproheme), 9 spectra with 90 min integration time (WT), 4 spectra with 40 min integration time (M149A), and 6 spectra with 60 min integration time $(\mathrm{Mb})$. 


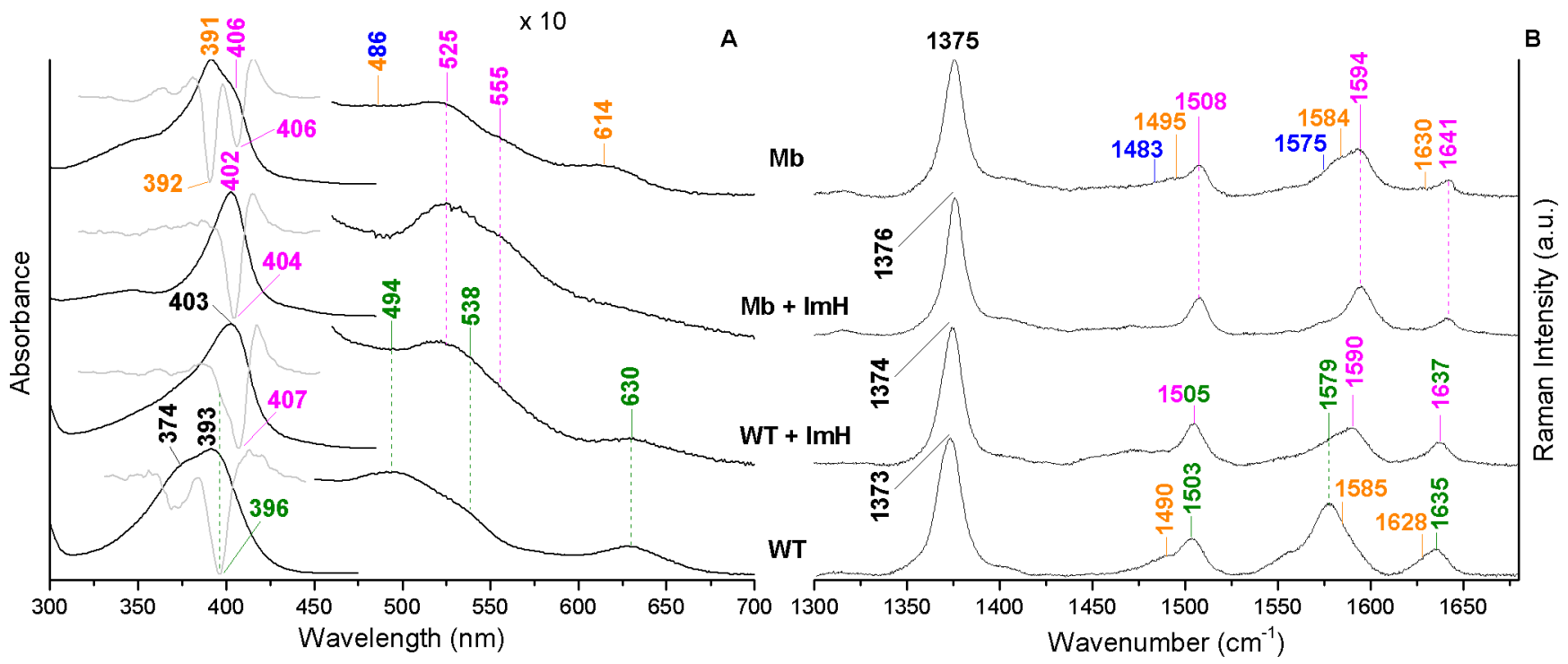

Figure 4. UV-vis absorption and second derivative spectra $\left(D^{2}\right)$ (Panel A) and RR spectra in the high frequency region (Panel B) of the coproheme complexes of WT and $\mathrm{Mb}$ with and without the addition of imidazole $(\mathrm{ImH})$. The band wavelengths and wavenumbers assigned to $5 \mathrm{cHS}, 5 \mathrm{cQS}$, $6 \mathrm{cHS}$, and 6cLS species are indicated in orange, olive green, blue, and magenta, respectively (see text). The spectra have been shifted along the ordinate axis to allow better visualization. The $450-700 \mathrm{~nm}$ region of the spectra in Panel A is expanded 10-fold. Experimental conditions of the RR spectra: $406.7 \mathrm{~nm}$ excitation wavelength, laser power at the sample $5 \mathrm{~mW}$; average of 9 spectra with 90 min integration time (WT), 10 spectra with $100 \mathrm{~min}$ integration time $(\mathrm{WT}+\mathrm{ImH}), 5$ spectra with $50 \mathrm{~min}$ integration time $(\mathrm{Mb}+\operatorname{ImH})$, and 6 spectra with 60 min integration time $(\mathrm{Mb})$.

Table 1. EPR Parameters of the Coproheme Complexes of LmChdC WT, Its M149 Mutant and Mb, Compared to Those of Soybean Peroxidase (SBP)

\begin{tabular}{|c|c|c|c|c|c|c|c|c|c|c|}
\hline \multirow[b]{2}{*}{ Protein } & \multirow[b]{2}{*}{$g_{1}$} & \multirow[b]{2}{*}{$g_{2}$} & \multirow[b]{2}{*}{$g_{3}$} & \multirow[b]{2}{*}{$g_{12}$} & \multirow[b]{2}{*}{ Assignment } & \multirow[b]{2}{*}{$R^{a} \%$} & \multirow[b]{2}{*}{$I^{b} \%$} & \multicolumn{3}{|c|}{$g$ strain } \\
\hline & & & & & & & & $g_{1}$ & $g_{2}$ & $g_{3}$ \\
\hline \multirow[t]{3}{*}{ WT } & 6.30 & 5.45 & 2.00 & 5.88 & $5 \mathrm{cHS}$ & 5.3 & 19 & 0.35 & 0.20 & 0.025 \\
\hline & 5.90 & 5.10 & 2.00 & 5.50 & $5 c Q S$ & 5.0 & 70 & 0.25 & 1.00 & 0.05 \\
\hline & 2.90 & 2.27 & $1.60^{c}$ & & $6 \mathrm{cLS}$ & & 11 & 0.15 & 0.08 & 0.15 \\
\hline \multirow[t]{3}{*}{ M149A } & 6.30 & 5.45 & 2.00 & 5.88 & $5 \mathrm{cHS}$ & 5.3 & 12 & 0.35 & 0.20 & 0.025 \\
\hline & 5.97 & 5.73 & 2.00 & 5.85 & $5 \mathrm{cHS}$ & 1.5 & 23 & 0.30 & 0.40 & 0.015 \\
\hline & 2.96 & 2.27 & $1.60^{c}$ & & $6 \mathrm{cLS}$ & & 65 & 0.15 & 0.08 & 0.15 \\
\hline \multirow[t]{3}{*}{$\mathrm{Mb}$} & 6.20 & 5.57 & 2.00 & 5.89 & $5 \mathrm{cHS}$ & 4.0 & 36 & 0.52 & 0.47 & 0.025 \\
\hline & 5.90 & 5.85 & 2.00 & 5.88 & $5 \mathrm{cHS}$ & 0.3 & 15 & 0.18 & 0.30 & 0.015 \\
\hline & 2.97 & 2.27 & $1.60^{c}$ & & $6 \mathrm{cLS}$ & & 49 & 0.15 & 0.08 & 0.15 \\
\hline \multirow[t]{2}{*}{$\mathrm{SBP}^{d}$} & 5.89 & 4.85 & 2.00 & 5.37 & $5 \mathrm{cQS}$ & & & & & \\
\hline & 3.25 & 2.07 & & & $6 \mathrm{cLS}$ & & & & & \\
\hline
\end{tabular}

${ }^{a} R$, rhombicity of HS signals were calculated according to Peisach et al. ${ }^{21}(\Delta g / 16) .{ }^{b}$ Approximate values. ${ }^{c}$ The $g_{3}$ band of the LS species is very broad and weak; hence, its value is approximate. ${ }^{d}$ From ref 22.

$1641\left(\nu_{10}\right) \mathrm{cm}^{-1}$ are assigned to a $6 \mathrm{cLS}$ species. These RR bands are strongly intensified with $406.7 \mathrm{~nm}$ excitation, but markedly lose intensity in the spectrum obtained with $356.4 \mathrm{~nm}$ excitation, in resonance with the Soret band at $392 \mathrm{~nm}$. This Soret band, together with the bands at 486 and $614 \mathrm{~nm}$, is assigned to the overlapping contribution of a $5 \mathrm{cHS}$ and a $6 \mathrm{cHS}$ species that, however, can be easily distinguished in the RR spectrum. The bands at $1495\left(\nu_{3}\right), 1584\left(\nu_{2}\right)$, and $1630\left(\nu_{10}\right)$ $\mathrm{cm}^{-1}$ are assigned to a $5 \mathrm{cHS}$ species and those at $1483\left(\nu_{3}\right)$, $1575\left(\nu_{2}\right)$, and $1618\left(\nu_{10}\right) \mathrm{cm}^{-1}$ to a $6 \mathrm{cHS}$ species. Therefore, as expected, with the $356.4 \mathrm{~nm}$ excitation, not only does the 6cLS spectrum markedly decrease in intensity, but interestingly, the $\nu_{2}$ band almost disappears. The loss of the $\nu_{2}$ band with this excitation is taken as a useful marker for the assignment of 6cLS species. In order to confirm these findings, we added imidazole to the WT in order to obtain a $6 \mathrm{cLS}$ heme as a model compound.
The exogenous imidazole does not bind completely the coproheme iron (Figure 4). Nevertheless, the bis-His complex is clearly observed, and is characterized by the same spectroscopic features observed for the $6 \mathrm{cLS}$ of the coproheme-Mb complex, its adduct with imidazole, and the coproheme-M149A mutant [Soret band at 403 and $407 \mathrm{~nm}$ in $\mathrm{D}^{2}$, visible bands at 525 and $555 \mathrm{~nm}$; core size $\mathrm{RR}$ bands at $1505\left(\nu_{3}\right), 1590\left(\nu_{2}\right)$ and $\left.1637\left(\nu_{10}\right) \mathrm{cm}^{-1}\right]$, all assigned to a 6cLS species. Taken together, these observations also strongly indicate that the heme state of coproheme-WT, characterized by a Soret at $393 \mathrm{~nm}$ (Figure 2) and RR bands at $1503\left(\nu_{3}\right)$, $1579\left(\nu_{2}\right)$, and $1635\left(\nu_{10}\right) \mathrm{cm}^{-1}$ (Figure 3), cannot be a 6cLS form. In analogy with the heme containing peroxidases belonging to Family 3 of the peroxidase-catalase superfamily, this form is assigned to a quantum mechanically mixed-spin (QS) state. ${ }^{15-17}$ In fact, as previously reported, ${ }^{15,31}$ the 5cQS species gives rise to (i) an electronic absorption spectrum similar to that of a $5 \mathrm{cHS}$ heme but with a shorter wavelength 


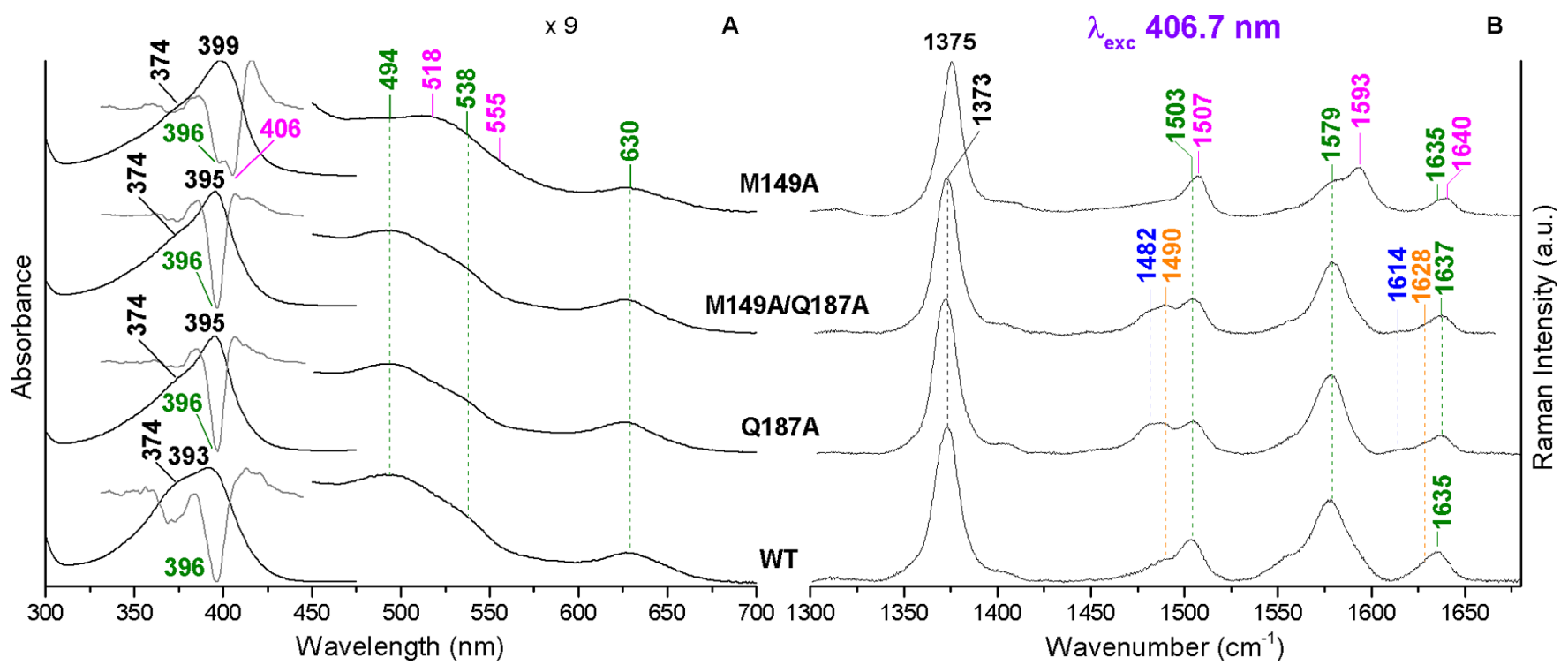

Figure 5. UV-vis absorption and second derivative $\left(\mathrm{D}^{2}\right)$ spectra (Panel A) and RR spectra in the high frequency region (Panel B) of the coproheme complexes with WT and the Q187A, M149A/Q187A, and M149A mutants. The band wavelengths and wavenumbers assigned to 5cHS, 5cQS, $6 \mathrm{cHS}$, and $6 \mathrm{cLS}$ species are indicated in orange, olive green, blue, and magenta, respectively. The spectra have been shifted along the ordinate axis to allow better visualization. The 450-700 nm region of the spectra in Panel A is expanded 9-fold. Experimental conditions of the RR spectra: 406.7 $\mathrm{nm}$ excitation wavelength, laser power at the sample of $5 \mathrm{~mW}$, average of 9 spectra with a 90 min integration time (WT), 14 spectra with a 140 min integration time (Q187A), 10 spectra with a 100 min integration time (M149A/Q187A), and 4 spectra with a 40 min integration time (M149A).

transitions; (ii) a CT band at 630-635 nm; (iii) RR core size marker bands frequencies similar to that of a $6 \mathrm{cLS}$ species; (iv) EPR spectra with $g_{12}$ values in the range $4<g_{12}<6$.

To gain further insight into the spin state and heme coordination of this species, the X-band EPR spectrum of the coproheme-WT complex was recorded (Figure S5 and Table 1). Three different species are present. The most abundant is characterized by $g$ values at 5.90, 5.10, $2.00\left(g_{12}=5.50\right)$, which confirms the presence of a $5 \mathrm{cQS}$ species. A $5 \mathrm{cHS}$ (6.30, 5.45, $\left.2.00 ; g_{12}=5.88\right)$, and a small amount of a $6 \mathrm{cLS}$ species (2.90, $2.27,1.60$ ) that is absent in the $R R$ room temperature spectrum, are also observed. In the case of the M149A mutant, in agreement with the RR spectra, the most abundant species is a 6 cLS form $(2.96,2.27,1.60)$. Its $g_{1}$ value $(2.96)$ is slightly higher than that of the WT LS species, possibly suggesting a more axial interaction of the heme ligand. Moreover, two different $5 \mathrm{cHS}$ species are present, one of which $(6.30,5.45$, 2.00; $\left.\mathrm{g}_{12}=5.88\right)$ is identical to that observed in the WT sample. In agreement with the RR spectra, the coproheme-Mb EPR spectrum is characterized by a dominant $6 \mathrm{cLS}$ form $(2.97,2.27$, $1.60)$, and two 5cHS species. One of the latter, the least abundant species, displays a very small rhombicity (5.90, 5.85, 1.99; $\left.g_{\perp}=5.88\right)$; hence, it can effectively be considered to be very close to a $6 \mathrm{cHS}$ form. Nevertheless, an alternative simulation using a pure $6 \mathrm{cHS}$ state produced a slightly poorer correspondence between experimental and simulated spectra.

The $g$ values of the $6 \mathrm{cLS}$ species for all three cases are similar to those of a bis-His heme coordination where the two imidazole planes are approximately parallel. ${ }^{32,33}$ Nevertheless, although there is a His residue in the coproheme- $\mathrm{Mb}$ complex, there are no His residues in the distal cavity of $\mathrm{ChdC}^{9}$ A possible alternative explanation of the $g_{1}$ signal for ChdC might be an $\mathrm{OH}^{-}-\mathrm{Fe}-\mathrm{His}$ species where the $\mathrm{OH}^{-}$ligand is strongly $\mathrm{H}$ bonded, as reported for HRPC and HRPA2 at alkaline $\mathrm{pH}^{34,35}$ However, the $\mathrm{H}$-bonding partner in the ChdC distal cavity is not obvious and at alkaline $\mathrm{pH}$ we did not observe any 6cLS hydroxo complex formation. In fact, in glycine, the buffer binds the heme iron, and with other buffers (e.g., borate) at alkaline $\mathrm{pH}$ we observed the release of the coproheme from the complex (data not shown). Conversely, the observation that the core-size RR bands of the coproheme-Mb-His complex are identical to those assigned to the $6 \mathrm{cLS}$ in coproheme- $\mathrm{Mb}$ (Figure 3B) is in complete agreement with the bis-His coordination determined from the EPR analysis.

Table 1 reports the EPR parameters of the coproheme complexes of LmChdC WT, its M149 mutant and Mb, compared to those of soybean peroxidase (SBP). Tables S1 and $S 2$ report the assignment of the UV-vis maxima and the main $\mathrm{RR}$ core-size marker bands of the various species.

To clarify this apparently inconsistent set of data and identify the nature of the sixth ligand in the LS coproheme-LmChdC complexes, we have considered which other key residues in the distal cavity might be able to bind the $\mathrm{Fe}$ atom via a $\mathrm{N}$ atom. Since the distal Gln residue (Q187 in $\mathrm{Lm}$ ), conserved in Firmicutes ChdC, has been shown to be particularly important in the stabilization of the distal side due to its interaction with incoming exogenous ligands, such as $\mathrm{CO},{ }^{12}$ we focused on this residue by studying the single Q187A and double Q187/ M149A variants.

Figure 5 compares the UV-vis and second derivative $\left(D^{2}\right)$ spectra (Panel A) and RR spectra in the high frequency region (Panel B) of the coproheme complexes of WT, and the Q187A, M149A/Q187A, and M149A mutants. In the absence of Q187, the spectra resemble very closely that of the WT and the $6 \mathrm{cLS}$ species, observed in the coproheme-M149A spectra (pink bands), completely disappears. Clearly, this allows us to conclude that the 6cLS species observed in this mutant is due to the Q187 residue, through binding of its $\mathrm{N}$ atom to the heme iron. Mutation of the Q187 residue also gives rise to a small amount of a $6 \mathrm{cHS}$ species (blue bands, $\nu_{3}$ and $\nu_{10}$ at 1482 and $1614 \mathrm{~cm}^{-1}$, respectively) at the expense of the $5 \mathrm{cQS}$ form. This suggests that the mutation also alters the H-bonding 

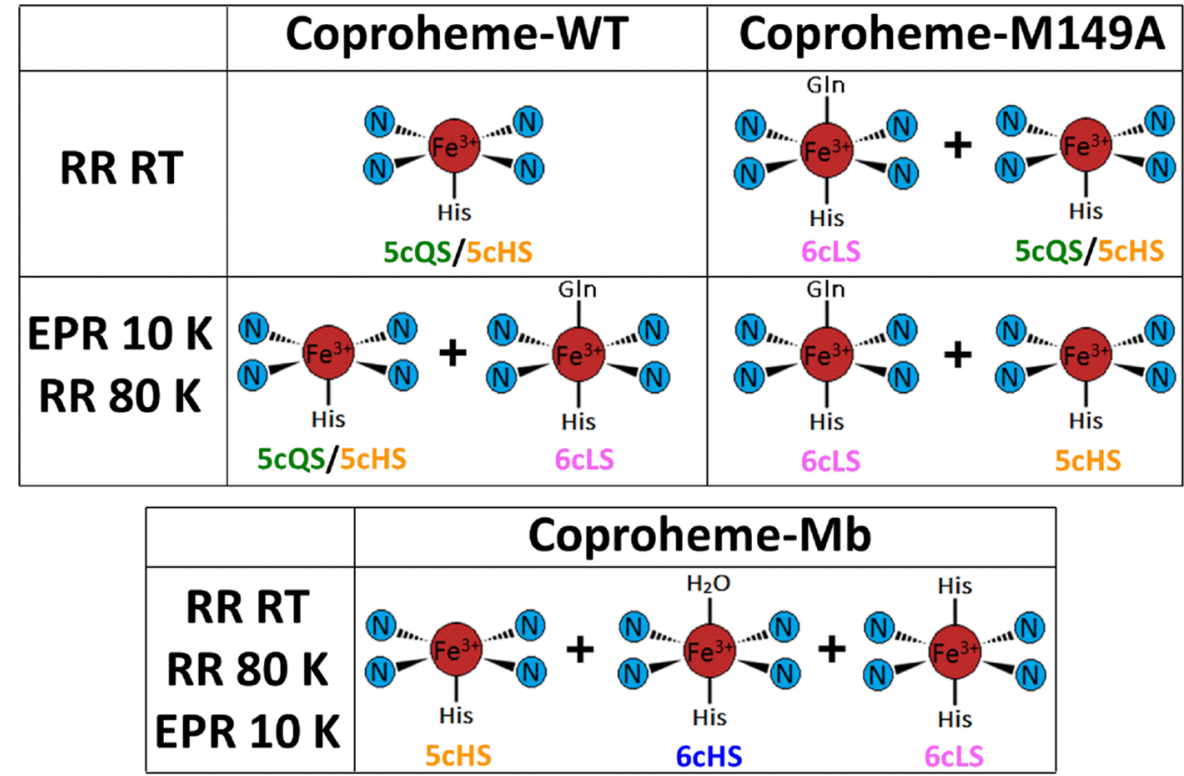

Figure 6. Heme coordination for the coproheme complexes of LmChdC, its M149A mutant, and Mb determined by RR and EPR spectroscopy at room and low temperatures..

network involving the conserved distal Arg133, propionate 6 and a water molecule. ${ }^{12}$

The EPR data are in very good agreement not only with the $\mathrm{RR}$ spectra at room temperature but also with those obtained at $80 \mathrm{~K}$ (Figures 6 and S6). The comparison between the $80 \mathrm{~K}$ RR spectra obtained for excitation at 356.4 and $406.7 \mathrm{~nm}$ confirms the presence of a $5 \mathrm{cQS}$ species $\left(\nu_{3} 1507, \nu_{2} 1584\right.$, and $\left.\nu_{10} 1637 \mathrm{~cm}^{-1}\right)$, a $5 \mathrm{cHS}$ species $\left(\nu_{3} 1490, \nu_{2} 1570\right.$ and $\nu_{10} 1627$ $\left.\mathrm{cm}^{-1}\right)$, and a $6 \mathrm{cLS}$ form $\left(\nu_{3} 1507, \nu_{2} 1594\right.$ and $\left.\nu_{10} 1640 \mathrm{~cm}^{-1}\right)$ for the WT, and mainly a $6 \mathrm{cLS}\left(\nu_{3} 1510, \nu_{2} 1597\right.$, and $\nu_{10} 1643$ $\left.\mathrm{cm}^{-1}\right)$ with only a small amount of $5 \mathrm{cHS}\left(\nu_{3} 1490, \nu_{2} 1570\right.$, and $\nu_{10} 1627 \mathrm{~cm}^{-1}$ ) for the M149 mutant (Figure S6). The $80 \mathrm{~K} \mathrm{RR}$ spectrum of coproheme-Mb complex is also characterized mainly by a $6 \mathrm{cLS}$ species $\left(\nu_{3} 1511, \nu_{2} 1599\right.$, and $\left.\nu_{10} 1646 \mathrm{~cm}^{-1}\right)$ and a small amount of $5 \mathrm{cHS}\left(\nu_{2} 1588 \mathrm{~cm}^{-1}\right)$ and $6 \mathrm{cHS}\left(\nu_{2}\right.$ $\left.1575 \mathrm{~cm}^{-1}\right)$ states. The slight differences between the RR frequencies of the 6cLS species of the M149A mutant and WT is consistent with the EPR analysis and suggests that the two 6cLS species differ in terms of ligand type or strength of ligand interaction with the heme iron. Moreover, the absence of any $5 c Q S$ species in the EPR and $80 \mathrm{~K} \mathrm{RR}$ spectra in the mutant suggests that a structural rearrangement may occur following mutation.

The previously reported analysis of ferric coprohemeLmChdC, based principally on UV-vis and EPR spectroscopies at $\mathrm{pH} 7$, concluded that the protein was characterized by the existence of a predominant high-spin state and a minor low spin form. ${ }^{10}$ The apparent contrast in assignment of the dominant spin state with that of the present study can be understood by taking into account a critically important difference between the respective samples. The previous study was conducted on proteins in phosphate buffer, which is known to cause possible artifacts in the EPR spectrum at low temperature. ${ }^{36}$ Accordingly, although the previously reported EPR spectrum has some similarities with that presented here, there are also important clear differences.

CO Complexes of the Coproheme and Heme $b$ WT and Mutant Proteins. In order to probe the properties of the distal cavity we studied the $\mathrm{CO}$ complexes of both the coproheme and heme $b$ WT and mutants. In fact, CO is a sensitive probe for investigating distal and proximal effects on ligand binding of heme proteins since back-donation from the Fe $\mathrm{d} \pi$ to the $\mathrm{CO} \pi^{*}$ orbitals is modulated by polar interactions with distal protein residues, which alters the electron distribution in the FeCO unit changing the order of the C$\mathrm{O}$ bond, and by variations in the donor strength of the trans ligand. ${ }^{37}$ A positively charged electrostatic field or $\mathrm{H}$-bond residues favors back-donation, strengthening the $\mathrm{Fe}-\mathrm{C}$ bond and correspondingly weakening the $\mathrm{C}-\mathrm{O}$ bond, thereby increasing the $\nu(\mathrm{FeC})$ vibrational frequencies and decreasing the $\nu(\mathrm{CO})$ frequencies. Conversely, a negatively charged electrostatic field has the opposite effect. ${ }^{38}$

As for heme protein- $\mathrm{CO}$ complexes, the ferrous coproheme proteins bind $\mathrm{CO}$ giving rise to a $6 \mathrm{cLS}$ species. The UV-vis spectra (Figure 7, panel A) are all blue-shifted compared to heme $b$ CO complexes (see below) due to the lack of conjugation of the vinyl groups in the coproheme complexes. Accordingly, the UV-vis spectrum of the coproheme-CO complex is characterized by a Soret band at $399 \mathrm{~nm}, 12 \mathrm{~nm}$ blue-shifted compared to that of the free heme-CO complex, ${ }^{39}$ with $\nu(\mathrm{FeC})$ and $\nu(\mathrm{CO})$ stretching modes at 530 and 1957 $\mathrm{cm}^{-1}$ (Figure 7, panel B), very similar to those observed for the heme-CO complex (at 530 and $1955 \mathrm{~cm}^{-1}$ ). ${ }^{39}$ The electronic absorption spectra of the WT and its selected mutants (M149A, Q187A, and M149A/Q187A) are very similar, with Soret, $\alpha$, and $\beta$ bands at 411, 531, and $559 \mathrm{~nm}$, respectively. Interestingly, the corresponding spectrum of coproheme-MbCO shows two bands in the Soret region at 400 and $409 \mathrm{~nm}$. However, the RR spectra obtained with both the 406.7 and $413.1 \mathrm{~nm}$ excitation wavelengths are identical (data not shown). For both excitation wavelengths, on the basis of the isotope shift in ${ }^{13} \mathrm{CO}$ versus ${ }^{12} \mathrm{CO}$ (Figure S7), two $\mathrm{CO}$ conformers have been identified characterized by (i) $\nu(\mathrm{FeC})$ at $503 \mathrm{~cm}^{-1}$ and $\nu(\mathrm{CO})$ at $1956 \mathrm{~cm}^{-1}$, and (ii) $\nu(\mathrm{FeC})$ at 510 $\mathrm{cm}^{-1}$ and $\nu(\mathrm{CO})$ at $1941 \mathrm{~cm}^{-1}$. Moreover, a weak band at 578 $\mathrm{cm}^{-1}$ assigned to the $\delta(\mathrm{FeCO})$ bending mode is observed (Figure 7, panel B). Coproheme-WT shows only one conformer with $\nu(\mathrm{FeC})$ at $508 \mathrm{~cm}^{-1}$ and $\nu(\mathrm{CO})$ at 1947 


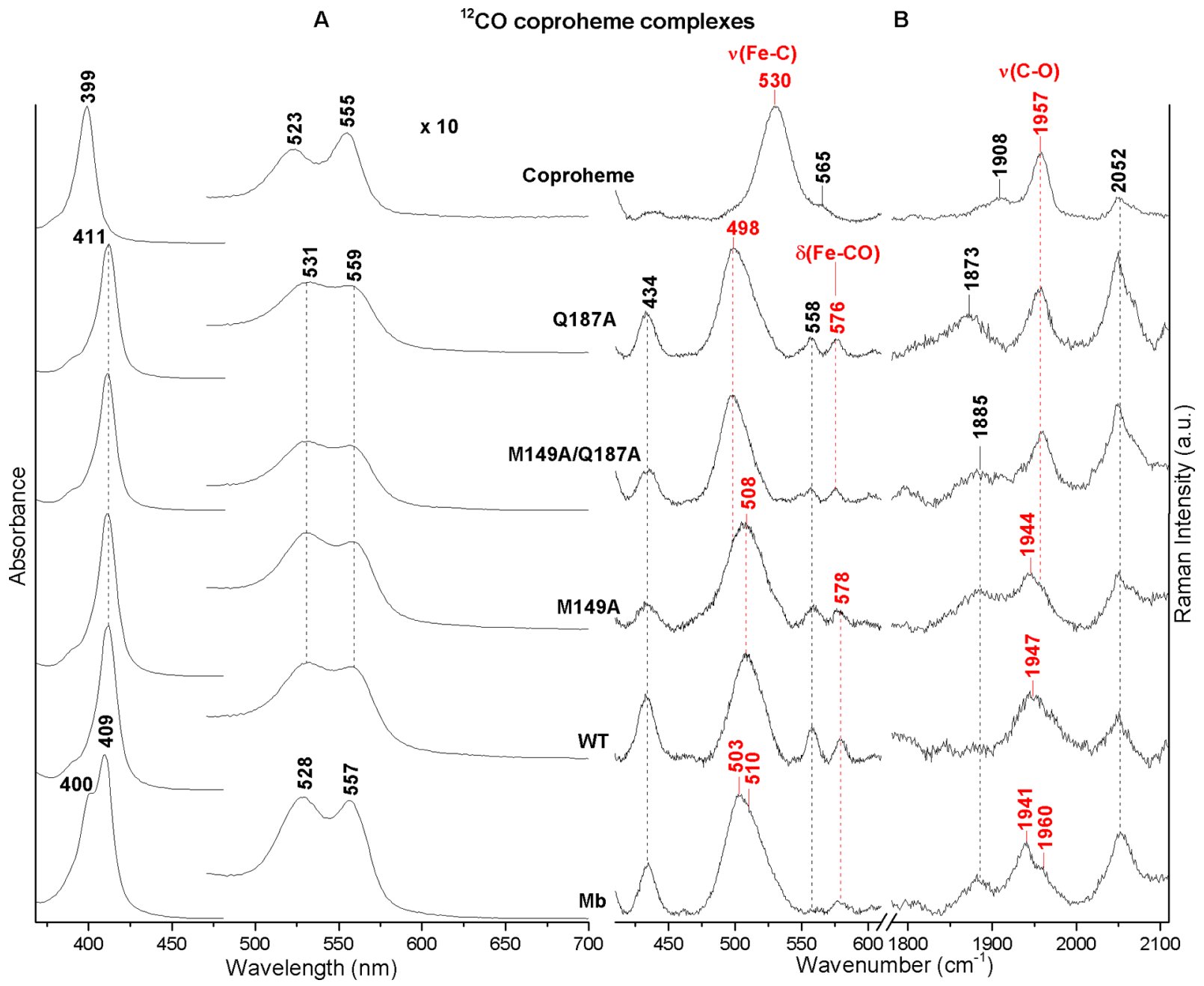

Figure 7. UV-vis (panel A) and RR (panel B) spectra in the low (left) and high (right) frequency regions of the ${ }^{12} \mathrm{CO}$ adducts of the coproheme complexes of Mb, WT, M149A, M149A/Q187A, Q187A, and coproheme. The frequencies of the $\nu(\mathrm{FeC}), \delta(\mathrm{FeCO})$, and $\nu(\mathrm{CO})$ modes are indicated in red. The spectra have been shifted along the ordinate axis to allow better visualization. Panel A: the 480-700 nm region is expanded 10fold. Panel B: experimental conditions: $\mathrm{Mb}$ and coproheme: $\lambda_{\text {exc }} 406.7 \mathrm{~nm}$, laser power at the sample $5 \mathrm{~mW}$, average of 4 spectra with $40 \mathrm{~min}$ integration time and 10 spectra with $100 \mathrm{~min}$ integration time in the low and high frequency regions, respectively (Mb), average of 6 spectra with 60 min integration time and 12 spectra with $120 \mathrm{~min}$ integration time in the low and high frequency regions, respectively (coproheme); WT and its mutants, $\lambda_{\text {exc }} 413.1 \mathrm{~nm}$, laser power at the sample 1-3 mW; average of 28 spectra with 280 min integration time and 22 spectra with 220 min integration time in the low and high frequency regions, respectively (WT), average of 6 spectra with 60 min integration time and 18 spectra with 180 min integration time in the low and high frequency regions, respectively (M149A), average of 6 spectra with 60 min integration time and 15 spectra with $150 \mathrm{~min}$ integration time in the low and high frequency regions, respectively (M149A/Q187A), and average of 9 spectra with 90 min integration time and 15 spectra with $150 \mathrm{~min}$ integration time in the low and high frequency regions, respectively (Q187A).

$\mathrm{cm}^{-1}$, similar to the frequencies observed in the M149A variant (508 and $1944 \mathrm{~cm}^{-1}$ ). In this variant, however, a second conformer is observed, characterized by $\nu(\mathrm{FeC})$ at $498 \mathrm{~cm}^{-1}$ and $\nu(\mathrm{CO})$ at $1957 \mathrm{~cm}^{-1}$, which is the only form present in the Q187A and M149A/Q187A mutants.

Figure 8 shows a plot of the $\nu(\mathrm{FeC})$ versus $\nu(\mathrm{CO})$ frequencies of the coproheme complexes of $\mathrm{LmChdC}$ and its variants, $\mathrm{Mb}$, coproheme, and the coproheme complexes of SaChdC and its variants. ${ }^{12} \mathrm{~A}$ negative linear correlation between the $\nu(\mathrm{FeC})$ and $\nu(\mathrm{CO})$ frequencies has been found for a large class of heme protein $\mathrm{CO}$ complexes and heme model compounds containing His as the fifth iron ligand. The line reported in Figure 8 has been obtained according to eq 1 of ref 37. The $\nu(\mathrm{FeC}) / \nu(\mathrm{CO})$ position along the correlation line reflects the type and strength of distal polar interactions. Above the imidazole back-bonding correlation line another parallel line is typical of heme proteins or model compounds with a trans ligand weaker than $\mathrm{His},{ }^{40}$ or no ligand at all. ${ }^{37,41}$ Similar to the free heme-CO complex, the free coproheme-CO complex lays on this line, in agreement with the formation of a 5cHS complex. ${ }^{39}$ The two conformers found for the $\mathrm{Mb}$ complex are reminiscent of those established for (heme $b$ ) sperm whale (SW) MbCO. At neutral $\mathrm{pH}$ two main conformers have been identified by $\mathrm{RR}$ and IR spectroscopy for the CO adduct of SWMb, named $A_{1}\left(508 / 1946 \mathrm{~cm}^{-1}\right)$ and $A_{3}\left(518 / 1932 \mathrm{~cm}^{-1}\right)$, with $A_{1}$ being the main species. In addition, a very weak species $\left(\mathrm{A}_{0}, 493 / 1965 \mathrm{~cm}^{-1}\right)$ is observed at neutral $\mathrm{pH}$ that increases at acid $\mathrm{pH}$ at the expense of the $\mathrm{A}_{1}$ conformer. ${ }^{42,43}$ The position of the distal His has been identified to be responsible for the different forms, which correspond to a closed $\left(A_{1}\right)$ and an open form $\left(A_{0}\right){ }^{43}$ Unlike $\mathrm{SWMb}$, for $\mathrm{HHMb}$ only one species has been identified by RR corresponding to form $\mathrm{A}_{1}$, ${ }^{44}$ while two $\nu(\mathrm{CO})$ stretching modes (at 1944 and $1932 \mathrm{~cm}^{-1}$ ) have been observed in the IR 


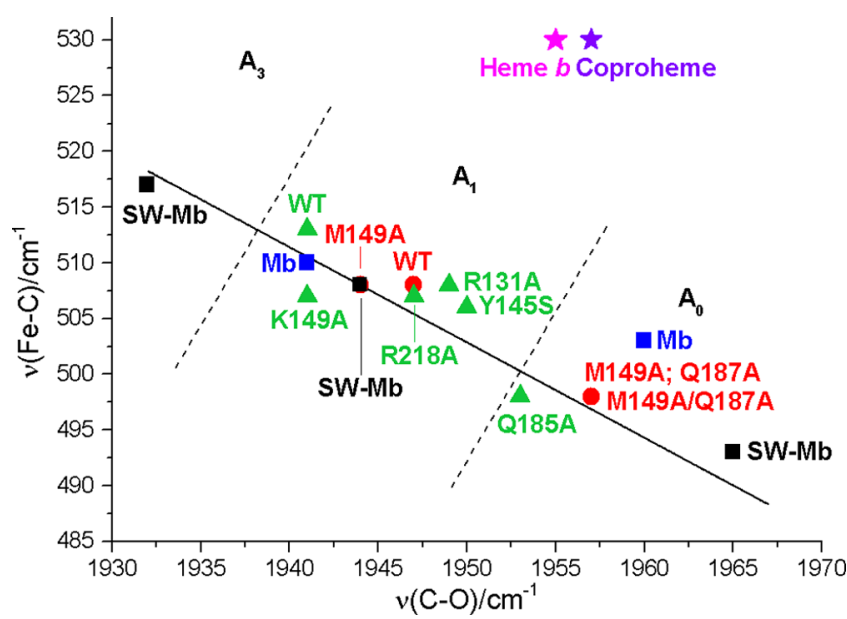

Figure 8. Back-bonding correlation line of the $\nu(\mathrm{Fe}-\mathrm{C})$ and $\nu(\mathrm{C}-\mathrm{O})$ stretching frequencies of the coproheme- $\mathrm{CO}$ complexes of $\mathrm{Mb}$ (blue solid squares), SaChdC WT, and selected mutants (green solid triangles), LmChdC WT and selected mutants (red solid circles), heme, and coproheme. The three conformers of SWMb (heme $b$ ) are also reported (black solid squares). The dotted lines indicate the approximate delineation between the frequency zones of the $A_{0}, A_{1}$, and $A_{3}$ states discussed in the text. The frequencies and references of the $\nu(\mathrm{Fe}-\mathrm{C})$ and $\nu(\mathrm{C}-\mathrm{O})$ stretching modes of the various $\mathrm{CO}$ adducts are reported in Table 2 .

spectrum, ${ }^{45}$ suggesting the presence also of form $A_{3}$. By analogy, we name the two conformers observed in the coproheme-Mb complex $\mathrm{A}_{1}\left(510 / 1941 \mathrm{~cm}^{-1}\right)$ and $\mathrm{A}_{0}$ (503/ $1956 \mathrm{~cm}^{-1}$ ), however, this latter form is not completely open but shows only a decreased polar interaction with the distal residues.

CO binds WT giving rise to only one conformer with frequencies that are similar to those of the more polar conformer $\left(A_{1}\right)$, while the M149A variant shows both the $A_{1}$ and $A_{0}$ forms. Since the $A_{1}$ species disappears upon replacement of the Q187 residue, its presence is due to the $\mathrm{H}$-bonding stabilization of $\mathrm{CO}$ by this residue. These results are in a very good agreement with those previously reported for the SaChdC-CO complexes. In particular, the WT complex showed a moderate $\mathrm{H}$-bond donation or electrostatic interaction with the bound $\mathrm{CO}$ and the distal Q185 residue. ${ }^{12}$

Unlike the coproheme-CO complexes, the heme $b$ protein CO adducts show very similar 6cLS CO spectra, with an overall 3-4 nm blue-shift of the UV-vis spectra compared to $\mathrm{HHMb}$ (Figure S8, panel A), consistent with the frequency upshift of one vinyl mode (data not shown) observed for the ferric heme $b$ proteins and, hence, lower vinyl conjugation with the heme. On the basis of their isotope shifts in ${ }^{13} \mathrm{CO}$ (Figure S9), the $\nu(\mathrm{FeC})$ bands of the WT and mutant $\mathrm{CO}$ adducts have been assigned to the band around $500 \mathrm{~cm}^{-1}$ present in all the proteins. The corresponding $\nu(\mathrm{CO})$ stretching mode is observed at $1960 \mathrm{~cm}^{-1}$ in the WT. Unfortunately, due to the high fluorescent background the corresponding $\nu(\mathrm{CO})$ stretching modes for all the mutants are not clearly defined. This form, similar to that found for the heme $b$ SaChdC-CO complexes $^{12}$ and identical to the $\mathrm{A}_{0}$ form found in the coproheme-CO complexes (Figure 8), shows a low polar interaction with distal residues (Table 2).
Table 2. $\nu(\mathrm{Fe}-\mathrm{C})$ and $\nu(\mathrm{C}-\mathrm{O})$ Stretching Modes

Frequencies $\left(\mathrm{cm}^{-1}\right)$ of the Coproheme- and Heme b-CO Adducts of the Proteins and Model Compounds Reported in Figure 8

\begin{tabular}{|c|c|c|c|c|}
\hline & Conformers & $\nu(\mathrm{FeC})$ & $\nu(\mathrm{CO})$ & ref \\
\hline \multicolumn{5}{|c|}{ coproheme } \\
\hline \multicolumn{5}{|l|}{$\mathrm{HH}$} \\
\hline $\mathrm{Mb}$ & $\mathrm{A}_{0}$ & 503 & 1960 & This work \\
\hline $\mathrm{Mb}$ & $\mathrm{A}_{1}$ & 510 & 1941 & This work \\
\hline \multicolumn{5}{|l|}{ Lm ChdC } \\
\hline WT & $\mathrm{A}_{1}$ & 508 & 1947 & This work \\
\hline M149A & $\mathrm{A}_{1}$ & 508 & 1944 & This work \\
\hline M149A & $\mathrm{A}_{0}$ & 498 & 1957 & This work \\
\hline Q187A & $\mathrm{A}_{0}$ & 498 & 1957 & This work \\
\hline M149A/Q187A & $\mathrm{A}_{0}$ & 498 & 1957 & This work \\
\hline \multicolumn{5}{|l|}{ SaChdC } \\
\hline WT & $\mathrm{A}_{1}$ & 513 & 1941 & 12 \\
\hline Y145S & $\mathrm{A}_{1}$ & 508 & 1949 & 12 \\
\hline $\mathrm{R} 218 \mathrm{~A}$ & $\mathrm{~A}_{1}$ & 507 & 1947 & 12 \\
\hline Q185A & $\mathrm{A}_{0} / \mathrm{A}_{1}$ & 498 & 1953 & 12 \\
\hline R131A & $\mathrm{A}_{1}$ & 506 & 1950 & 12 \\
\hline K149A & $A_{1}$ & 507 & 1941 & 12 \\
\hline Coproheme & & 530 & 1957 & This work \\
\hline \multicolumn{5}{|c|}{ Heme $b$} \\
\hline \multicolumn{5}{|l|}{ SW } \\
\hline $\mathrm{Mb}$ & $\mathrm{A}_{3}$ & 517 & 1932 & 42,43 \\
\hline $\mathrm{Mb}$ & $\mathrm{A}_{1}$ & 508 & 1944 & 42,43 \\
\hline $\mathrm{Mb}$ & $\mathrm{A}_{0}$ & 493 & 1965 & 42,43 \\
\hline \multicolumn{5}{|l|}{$\mathrm{HH}$} \\
\hline $\mathrm{Mb}$ & $\mathrm{A}_{3}$ & - & 1932 & 45 \\
\hline $\mathrm{Mb}$ & $\mathrm{A}_{1}$ & 509 & 1944 & 44 \\
\hline Lm ChdC WT & $\mathrm{A}_{0}$ & 500 & 1960 & This work \\
\hline Sa ChdC WT & $\mathrm{A}_{0}$ & 498 & 1958 & 12 \\
\hline Heme $b$ & & 530 & 1955 & 39 \\
\hline
\end{tabular}

\section{DISCUSSION}

The electronic absorption spectra of coproheme-LmChdC WT are very similar to the corresponding spectra of SaChdC, the latter being characterized by Soret, visible $\alpha / \beta$, and CT 1 bands at 394, 497/533, and $630 \mathrm{~nm}$, respectively. However, the RR spectra of the two proteins are different. In particular, the coproheme-SaChdC complex is characteristic of a $5 \mathrm{cHS}$ form and no species with high frequencies corresponding to a $Q S$ state have been observed. ${ }^{11}$

The QS spin state is very rare in heme proteins. Moreover, not only is its possible involvement in protein function unclear, but the structural determinants of $5 \mathrm{cQS}$ vs $5 \mathrm{cHS}$ spin states have also been a matter of extensive debate and remain elusive. $^{14,15}$ The formation of a 5cQS heme has been mainly associated with a weak axial ligand. However, this feature does not appear to be sufficient to cause a QS state. In fact, while the lack of a H-bonding partner for the proximal imidazole ligand may account for the presence of a $5 \mathrm{cQS}$ state in cytochromes $c^{\prime},{ }^{14}$ heme-containing peroxidases are characterized by a conserved strong $\mathrm{H}$-bond between the $\mathrm{N}_{\delta}$ atom of the imidazole ligand and the carboxylate of an aspartic side chain, which acts as H-bond acceptor, imparting an imidazolate character to the histidine ligand. ${ }^{15,16}$ Interestingly, in both ferrous coproheme-LmChdC and -SaChdC, the $\nu(\mathrm{Fe}-\mathrm{Im})$ stretching mode is observed at $214 \mathrm{~cm}^{-1}$, 9,11 confirming that the $\mathrm{N}_{\varepsilon}$ of the imidazole of the proximal His ( $\left.\mathrm{H} 174\right)$ is weakly bonded to the heme iron in agreement with the crystal 

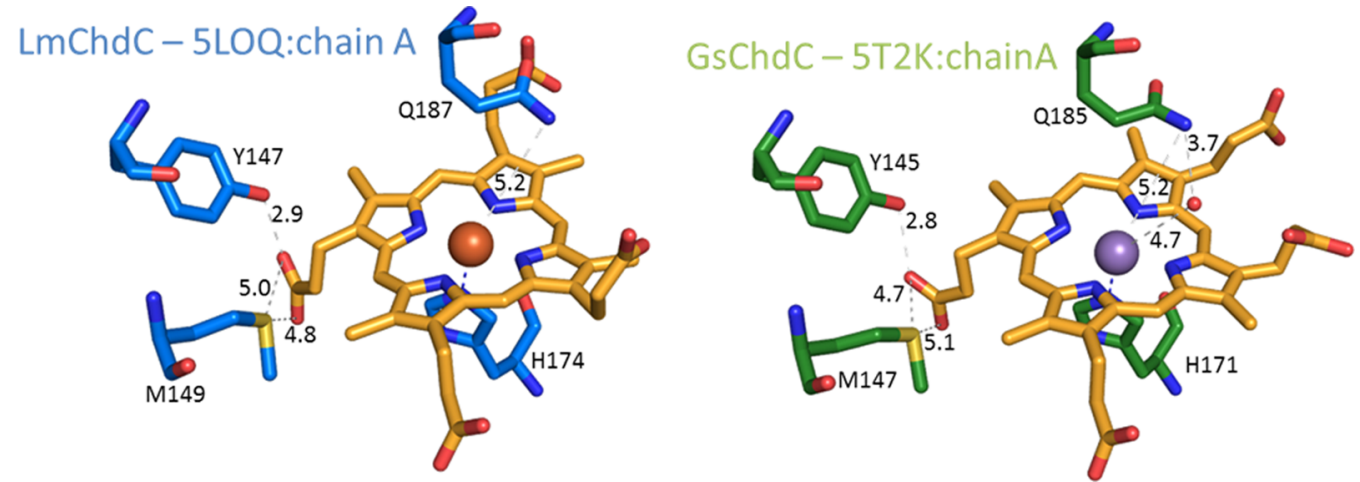

Figure 9. Active site architecture of LmChdC and GsChdC. LmChdC is depicted in blue and GsChdC in green. Distances are shown as gray dashes and labeled in black.

structure (5LOQ). However, as mentioned above, coprohemeSaChdC does not display a QS state. ${ }^{11}$

As an initial step in the decarboxylase reaction mechanism, coproheme decarboxylases must bind the substrate coproheme prior to reaction with hydrogen peroxide. The coproheme binding constants for LmChdC and SaChdC have been reported previously ${ }^{10}$ and have demonstrated that the large substrate finds its way into the binding pocket very rapidly. Coproheme binding to the M149A variant is WT-like (Figure S2), but the final spectrum differs from that of WT in terms of its spin states (Figure 2). Binding of coproheme $\left(k_{\text {on }}\right)$ to the Q187A variant and the double mutant M149A/Q187A is significantly lower than for WT, whereas the second phase, referred to as the rearrangement phase, is similar to the WT protein in these variants. The M149A variant is an exception since the rearrangement phase is faster (Figure S2). The residue Q187, which acts as internal ligand causing the 6cLS in the M149A variant, is part of the active site and is located on the distal heme side. In the available crystal structures, its amino acid side chain has been found to point away from the heme and is more than $5 \AA$ distant from the heme iron (Figure 9). Therefore, the distal cavity appears to be very flexible, and its flexibility appears to be confirmed by the finding that in the M149A variant two CO conformers have been found which resemble the open $\left(A_{0}\right)$ and closed $\left(A_{1}\right)$ conformations observed in SWMb-CO. ${ }^{43}$ We suggest that the Q187 residue has a similar role to that of the distal His in native SWMb: in the absence of the $\mathrm{Q} 187$ residue only the $\mathrm{A}_{0}$ conformer is observed in the single Q187A and M149A/Q187A double variants. The interaction between M149 and propionyl 2 has an important role in keeping the Q187 residue correctly positioned to close the distal cavity. This is confirmed by the $\mathrm{CO}$ adducts of the two heme $b$-ChdCs considered herein, both of which show only the $A_{0}$ conformer.

Interestingly, Q187 is not essential for the reactivity of coproheme with hydrogen peroxide to yield the threepropionate intermediate and, subsequently, heme $b$; however, its role is clearly non-negligible. Therefore, it is suggested to be important for the active site architecture. Moreover, the Q187A and M149A/Q187A variants are much more prone to heme bleaching during the catalytic reaction than the WT and M149A single variant (Figure S3). The stoichiometric excess of hydrogen peroxide needed to fully convert coproheme to heme $b$ is WT-like for the M149A mutants, whereas when Q187 is mutated the reaction is less efficient and a higher excess of hydrogen peroxide is needed (Figure S3D). Since the turnover number $\left(k_{\text {cat }}\right)$ for the Q187A mutant is WT-like, but the $K_{\mathrm{M}^{-}}$ value is 5.6-fold higher and heme bleaching is more pronounced in this variant, Q187 most probably has a significant role in binding and stabilization of the incoming hydrogen peroxide (Figure S3E). A similar role for this residue was already proposed in SaChdC. ${ }^{12}$ Q187 is conserved in Firmicutes (clade 1); in active ChdCs from Actinobacteria (clade 2) an alanine can be found at the corresponding position. ${ }^{5}$ Interestingly, actinobacterial ChdCs are not prone to heme bleaching and convert coproheme more efficiently to heme $b$ than ChdCs from Firmicutes. ${ }^{5}$ In these clade 2 ChdCs another player has to take over the role of Q187 in LmChdC. The 4.7-fold higher $K_{\mathrm{M}}$-value of the M149A variant (Figure $\mathrm{S} 3 \mathrm{E})$ compared to the WT can be explained by the presence of the 6cLS species resulting from the binding of the Q187 residue, which has to be displaced by the incoming hydrogen peroxide. Therefore, M149 is also suggested to be important for the active site architecture, as upon its exchange with alanine, Q187 moves closer to the heme iron and can act as a low-spin ligand.

Furthermore, we propose that M149 is involved in the formation of a covalent bond with one vinyl substituent of modified heme $b$ mediated by excess hydrogen peroxide (Figure 1). Most probably a sulfonium ion linkage is established, as has been demonstrated for human myeloperoxidase $^{24}$ and the S160M variant of ascorbate peroxidase. ${ }^{46}$ This (autocatalytic) radical mechanism typically starts by the formation of Compound I upon reaction of the ferric heme $b$ enzyme with hydrogen peroxide. In these peroxidases Compound I initiates this reaction by oxidizing the adjacent Met side chain. In coproheme decarboxylases, Compound I is hypothesized to be the redox intermediate that leads to initiation of coproheme decarboxylation. ${ }^{9,12,46}$ It cannot be excluded that the observed cross-linking might be an in vitro artifact that occurs due to the use of $\mathrm{H}_{2} \mathrm{O}_{2}$ concentrations higher than those found under physiological conditions. Nevertheless, it is also possible that it is physiologically relevant as a potential rescue mechanism to avoid undesirable oxidative side reactions. In the latter scenario, heme $b$ would be covalently sequestered in the case where too much $\mathrm{H}_{2} \mathrm{O}_{2}$ is present and, subsequently, the protein together with the linked heme would be degraded. The equilibrium of heme biosynthesis and degradation is crucial to any organism and utilizes many different strategies. ${ }^{47}$ 


\section{CONCLUSIONS}

In this work we have presented a thorough investigation of the active site architecture of coproheme decarboxylase WT and selected variants from Listeria monocytogenes using various spectroscopic techniques and also probed the impact of conserved active site amino acids on its catalytic activity. The M149 and Q187 residues are conserved throughout the clade 1 coproheme decarboxylases, which are constituted by representatives from Firmicutes, Thermi, and Euryarcheota., ${ }^{5,17}$ In contrast to coproheme-SaChdC WT, ferric coprohemeLmChdC WT is predominantly characterized by the uncommon $5 \mathrm{cQS}$ state, even though the same conserved residues constitute the active site architecture. Further differences between $\mathrm{LmChdC}$ and SaChdC concern the degree of heme bleaching during the reaction of the coproheme-bound ChdC with hydrogen peroxide. SaChdC requires a higher stoichiometric excess $(5 \text {-fold })^{12}$ for complete turnover (coproheme to heme $b$ ) than LmChdC (2-fold). ${ }^{9}$ Heme bleaching in the WT enzymes is more pronounced in SaChdC, as no isosbestic point can be observed in the UV-vis spectra of hydrogen peroxide titrations of the coproheme-bound enzyme, ${ }^{11}$ in contrast to $\mathrm{LmChdC} .^{9}$ Interestingly, in a similar manner, superimposable active site architectures of chlorite dismutases from different phylogenetic clades display surprisingly pronounced differences concerning catalytic parameters, ligand binding constants, or inactivation mechanisms. ${ }^{48-51}$ M149 and Q187 have been shown to be structurally important for the active site architecture of the coproheme-bound enzyme, as highlighted by the observed catalytic and spectroscopic differences of the mutants. The features of the respective active site architectures of other ChdCs will be the targets of further investigation to gain a more comprehensive insight into the function and mechanism of ChdCs. Notably, a phenylalanine can be found at the M149 position in clade 2 and $4 \mathrm{ChdCs}^{5}$ and an alanine (clade 2) or leucine (clade 4) at the Q187 position.

\section{ASSOCIATED CONTENT}

\section{S Supporting Information}

The Supporting Information is available free of charge on the ACS Publications website at DOI: 10.1021/acs.biochem.8b00186.

UV-vis absorption, second derivative, and high frequency region RR spectra; Coproheme binding to the LmChdC variants; Enzymatic activity of the LmChdC M149A, Q187A, and M149A/Q187A variants; EPR spectra; UV-vis and RR core size band assignments of coproheme and coproheme complexes; UV-vis and $\mathrm{RR}$ spectra in the low and high frequency regions (PDF)

\section{AUTHOR INFORMATION}

\section{Corresponding Author}

*E-mail: giulietta.smulevich@unifi.it. Phone: +39-055-4573083. ORCID

Stefan Hofbauer: 0000-0003-3375-7715

Paul G. Furtmüller: 0000-0002-1199-2469

Christian Obinger: 0000-0002-7133-3430

Giulietta Smulevich: 0000-0003-3021-8919

Notes

The authors declare no competing financial interest.

\section{ACKNOWLEDGMENTS}

We thank Daniel Maresch for technical support performing mass spectrometry analysis. This project was supported by the Austrian Science Fund, FWF [stand-alone project P29099].

\section{ABBREVIATIONS}

coproheme, iron coproporphyrin III; ChdC, coproheme decarboxylase; LmChdC, ChdC from Listeria monocytogenes; $\mathrm{WT}$, wild-type of ferric coproheme-LmChdC; $\mathrm{Mb}$, ferric myoglobin; $\mathrm{HH}$, horse heart; SW, sperm whale; coproheme$\mathrm{Mb}$, coproheme bound myoglobin complex; M149A, LmChdC Met149Ala variant; Q187A, LmChdC Gln187Ala variant; M149A/Q187A, LmChdC Met149Ala/Gln187Ala double variant; $\mathrm{SBP}$, soybean peroxidase; $\mathrm{CT} 1$, charge-transfer band due to $\mathrm{a}_{2 \mathrm{u}}(\pi) \rightarrow \mathrm{e}_{\mathrm{g}}(\mathrm{d} \pi)$ transition; 5c, five-coordinated; $6 \mathrm{c}$, sixcoordinated; HS, high spin; LS, low spin; RR, resonance Raman; EPR, electron paramagnetic resonance; QS, quantum mechanically mixed spin

\section{REFERENCES}

(1) Dailey, T. A., Boynton, T. O., Albetel, A. N., Gerdes, S., Johnson, M. K., and Dailey, H. A. (2010) Discovery and Characterization of HemQ: an essential heme biosynthetic pathway component. J. Biol. Chem. 285, 25978-25986.

(2) Dailey, H. A., Gerdes, S., Dailey, T. A., Burch, J. S., and Phillips, J. D. (2015) Noncanonical coproporphyrin-dependent bacterial heme biosynthesis pathway that does not use protoporphyrin. Proc. Natl. Acad. Sci. U. S. A. 112, 2210-2215.

(3) Dailey, H. A., Dailey, T. A., Gerdes, S., Jahn, D., Jahn, M., O'Brian, M. R. and Warren, M. J. (2017) Prokaryotic Heme Biosynthesis: Multiple Pathways to a Common Essential Product. Microbiol. Mol. Biol. Rev. 81 (1), e00048-16.

(4) Kosugi, N., Araki, T., Fujita, J., Tanaka, S., and Fujiwara, T. (2017) Growth phenotype analysis of heme synthetic enzymes in a halophilic archaeon, Haloferax volcanii. PLoS One 12, e0189913.

(5) Pfanzagl, V., Holcik, L., Maresch, D., Gorgone, G., Michlits, H., Furtmüller, P. G., and Hofbauer, S. (2018) Coproheme decarboxylases - Phylogenetic prediction versus biochemical experiments. Arch. Biochem. Biophys. 640, 27-36.

(6) Hobbs, C., Dailey, H. A., and Shepherd, M. (2016) The HemQ coprohaem decarboxylase generates reactive oxygen species: implications for the evolution of classical haem biosynthesis,. Biochem. J. 473, 3997-4009.

(7) Mayfield, J. A., Hammer, N. D., Kurker, R. C., Chen, T. K., Ojha, S., Skaar, E. P., and DuBois, J. L. (2013) The chlorite dismutase (HemQ) from Staphylococcus aureus has a redox-sensitive heme and is associated with the small colony variant phenotype,. J. Biol. Chem. 288, 23488-23504.

(8) Hofbauer, S., Hagmüller, A., Schaffner, I., Mlynek, G., Krutzler, M., Stadlmayr, G., Pirker, K. F., Obinger, C., Daims, H., DjinovićCarugo, K., and Furtmüller, P. G. (2015) Structure and heme-binding properties of HemQ (chlorite dismutase-like protein) from Listeria monocytogenes. Arch. Biochem. Biophys. 574, 36-48.

(9) Hofbauer, S., Mlynek, G., Milazzo, L., Puhringer, D., Maresch, D., Schaffner, I., Furtmüller, P. G., Smulevich, G., Djinovic-Carugo, K., and Obinger, C. (2016) Hydrogen peroxide-mediated conversion of coproheme to heme b by HemQ-lessons from the first crystal structure and kinetic studies. FEBS J. 283, 4386-4401.

(10) Hofbauer, S., Dalla Sega, M., Scheiblbrandner, S., Jandova, Z., Schaffner, I., Mlynek, G., Djinovic-Carugo, K., Battistuzzi, G., Furtmüller, P. G., Oostenbrink, C., and Obinger, C. (2016) Chemistry and Molecular Dynamics Simulations of Heme b-HemQ and Coproheme-HemQ. Biochemistry 55, 5398-5412.

(11) Celis, A. I., Streit, B. R., Moraski, G. C., Kant, R., Lash, T. D., Lukat-Rodgers, G. S., Rodgers, K. R., and DuBois, J. L. (2015) Unusual 
Peroxide-Dependent, Heme-Transforming Reaction Catalyzed by HemQ. Biochemistry 54, 4022-4032.

(12) Celis, A. I., Gauss, G. H., Streit, B. R., Shisler, K., Moraski, G. C., Rodgers, K. R., Lukat-Rodgers, G. S., Peters, J. W., and DuBois, J. L. (2017) Structure-Based Mechanism for Oxidative Decarboxylation Reactions Mediated by Amino Acids and Heme Propionates in Coproheme Decarboxylase (HemQ). J. Am. Chem. Soc. 139, 19001911.

(13) Streit, B. R., Celis, A. I., Shisler, K., Rodgers, K. R., LukatRodgers, G. S., and DuBois, J. L. (2017) Reactions of Ferrous Coproheme Decarboxylase (HemQ) with $\mathrm{O} 2$ and $\mathrm{H} 2 \mathrm{O} 2$ Yield Ferric Heme b. Biochemistry 56, 189-201.

(14) Hough, M. A., and Andrew, C. R. (2015) Cytochromes c': Structure, Reactivity and Relevance to Haem-Based Gas Sensing. Adv. Microb. Physiol. 67, 1-84.

(15) Smulevich, G., Feis, A., and Howes, B. D. (2005) Fifteen years of Raman spectroscopy of engineered heme containing peroxidases: what have we learned? Acc. Chem. Res. 38, 433-440.

(16) Smulevich, G., Howes, B. D., and Droghetti, E. (2016) Structural and Functional Properties of Heme-containing Peroxidases: a Resonance Raman Perspective for the Superfamily of Plant, Fungal and Bacterial Peroxidases, In Heme Peroxidases (Raven, E., and Dunford, B., Eds.), pp 61-98, The Royal Society of Chemistry.

(17) Zámocký, M., Hofbauer, S., Schaffner, I., Gasselhuber, B., Nicolussi, A., Soudi, M., Pirker, K. F., Furtmüller, P. G., and Obinger, C. (2015) Independent evolution of four heme peroxidase superfamilies. Arch. Biochem. Biophys. 574, 108-119.

(18) Teale, F. W. (1959) Cleavage of the haem-protein link by acid methylethylketone. Biochim. Biophys. Acta 35, 543.

(19) Le, P., Zhao, J., and Franzen, S. (2014) Correlation of heme binding affinity and enzyme kinetics of dehaloperoxidase. Biochemistry $53,6863-6877$.

(20) Stoll, S., and Schweiger, A. (2006) EasySpin, a comprehensive software package for spectral simulation and analysis in EPR. J. Magn. Reson. 178, 42-55.

(21) Peisach, J., Blumberg, W. E., Ogawa, S., Rachmilewitz, E. A., and Oltzik, R. (1971) The effects of protein conformation on the heme symmetry in high spin ferric heme proteins as studied by electron paramagnetic resonance,. J. Biol. Chem. 246, 3342-3355.

(22) Aasa, R, and Vänngard, T. (1975) EPR signal intensity and powder shapes. Reexamination. J. Magn. Reson. 19, 308-315.

(23) Nelson, D. P., and Kiesow, L. A. (1972) Enthalpy of decomposition of hydrogen peroxide by catalase at 25 degrees $\mathrm{C}$ (with molar extinction coefficients of $\mathrm{H} 2 \mathrm{O} 2$ solutions in the UV). Anal. Biochem. 49, 474-478.

(24) Fiedler, T. J., Davey, C. A., and Fenna, R. E. (2000) X-ray crystal structure and characterization of halide-binding sites of human myeloperoxidase at 1.8 A resolution. J. Biol. Chem. 275, 11964-11971.

(25) Zederbauer, M., Furtmüller, P. G., Ganster, B., Moguilevsky, N., and Obinger, C. (2007) The vinyl-sulfonium bond in human myeloperoxidase: impact on compound I formation and reduction by halides and thiocyanate,. Biochem. Biophys. Res. Commun. 356, 450456.

(26) Brogioni, S., Stampler, J., Furtmüller, P. G., Feis, A., Obinger, C., and Smulevich, G. (2008) The role of the sulfonium linkage in the stabilization of the ferrous form of myeloperoxidase: a comparison with lactoperoxidase,. Biochim. Biophys. Acta, Proteins Proteomics 1784, 843-849.

(27) Battistuzzi, G., Stampler, J., Bellei, M., Vlasits, J., Soudi, M., Furtmüller, P. G., and Obinger, C. (2011) Influence of the covalent heme-protein bonds on the redox thermodynamics of human myeloperoxidase. Biochemistry 50, 7987-7994.

(28) Marzocchi, M., and Smulevich, G. (2003) Relationship between heme vinyl conformation and the protein matrix in peroxidases. $J$. Raman Spectrosc. 34, 725-736.

(29) Feis, A., Tofani, L., De Sanctis, G., Coletta, M., and Smulevich, G. (2007) Multiphasic kinetics of myoglobin/sodium dodecyl sulfate complex formation. Biophys. J. 92, 4078-4087.
(30) Choi, S., Spiro, T. G., Langry, K. C., Smith, K. M., Budd, D. L., and La Mar, G. N. (1982) Structural correlations and vinyl influences in resonance Raman spectra of protoheme complexes and proteins. J. Am. Chem. Soc. 104, 4345-4351.

(31) Indiani, C., Feis, A., Howes, B. D., Marzocchi, M. P., and Smulevich, G. (2000) Effect of low temperature on soybean peroxidase: spectroscopic characterization of the quantum-mechanically admixed spin state. J. Inorg. Biochem. 79, 269-274.

(32) Walker, F. (1999) Magnetic spectroscopic (EPR, ESEEM, Mossbauer, MCD and NMR) studies of low-spin ferriheme centers and their corresponding heme proteins. Coord. Chem. Rev. 185-6, 471-534.

(33) Brautigan, D. L., Feinberg, B. A., Hoffman, B. M., Margoliash, E., Preisach, J., and Blumberg, W. E. (1977) Multiple low spin forms of the cytochrome $c$ ferrihemochrome. EPR spectra of various eukaryotic and prokaryotic cytochromes c. J. Biol. Chem. 252, 574-582.

(34) Howes, B. D., Feis, A., Indiani, C., Marzocchi, M. P., and Smulevich, G. (2000) Formation of two types of low-spin heme in horseradish peroxidase isoenzyme $\mathrm{A} 2$ at low temperature. JBIC, J. Biol. Inorg. Chem. 5, 227-235.

(35) Blumberg, W. E., Peisach, J., Wittenberg, B. A., and Wittenberg, J. B. (1968) The electronic structure of protoheme proteins. I. An electron paramagnetic resonance and optical study of horseradish peroxidase and its derivatives,. J. Biol. Chem. 243, 1854-1862.

(36) Williams-Smith, D. L., Bray, R. C., Barber, M. J., Tsopanakis, A. D., and Vincent, S. P. (1977) Changes in apparent $\mathrm{pH}$ on freezing aqueous buffer solutions and their relevance to biochemical electronparamagnetic-resonance spectroscopy. Biochem. J. 167, 593-600.

(37) Spiro, T. G., and Wasbotten, I. H. (2005) CO as a vibrational probe of heme protein active sites. J. Inorg. Biochem. 99, 34-44.

(38) Phillips, G., Teodoro, M., Li, T., Smith, B., and Olson, J. (1999) Bound $\mathrm{CO}$ is a molecular probe of electrostatic potential in the distal pocket of myoglobin. J. Phys. Chem. B 103, 8817-8829.

(39) Ye, X., Yu, A., Georgiev, G. Y., Gruia, F., Ionascu, D., Cao, W., Sage, J. T., and Champion, P. M. (2005) CO rebinding to protoheme: investigations of the proximal and distal contributions to the geminate rebinding barrier. J. Am. Chem. Soc. 127, 5854-5861.

(40) Vogel, K., Kozlowski, P., Zgierski, M., and Spiro, T. (2000) Role of the axial ligand in heme-CO backbonding; DFT analysis of vibrational data. Inorg. Chim. Acta 297, 11-17.

(41) Ray, G., Li, X., Ibers, J., Sessler, J., and Spiro, T. (1994) How far can proteins bend the FeCO unit. - Distal polar and steric effects in heme proteins and models. J. Am. Chem. Soc. 116, 162-176.

(42) Howes, B. D., Helbo, S., Fago, A., and Smulevich, G. (2012) Insights into the anomalous heme pocket of rainbow trout myoglobin. J. Inorg. Biochem. 109, 1-8.

(43) Morikis, D., Champion, P., Springer, B., and Sligar, S. (1989) Resonance Raman investigations of site-directed mutants of Myoglobin - Effects of distal Histidine replacement. Biochemistry 28, $4791-4800$

(44) Smulevich, G., Mantini, A. R., Paoli, M., Coletta, M., and Geraci, G. (1995) Resonance Raman studies of the heme active site of the homodimeric myoglobin from Nassa mutabilis: a peculiar case. Biochemistry 34, 7507-7516.

(45) Nagao, S., Ishikawa, H., Yamada, T., Mizutani, Y., and Hirota, S. (2015) Carbon monoxide binding properties of domain-swapped dimeric myoglobin. JBIC, J. Biol. Inorg. Chem. 20, 523-530.

(46) Metcalfe, C. L., Ott, M., Patel, N., Singh, K., Mistry, S. C., Goff, H. M., and Raven, E. L. (2004) Autocatalytic formation of green heme: evidence for $\mathrm{H} 2 \mathrm{O} 2$-dependent formation of a covalent methionineheme linkage in ascorbate peroxidase. J. Am. Chem. Soc. 126, 1624216248.

(47) Sheldon, J. R., and Heinrichs, D. E. (2015) Recent developments in understanding the iron acquisition strategies of gram positive pathogens. FEMS Microbiol Rev. 39, 592-630.

(48) Geeraerts, Z., Celis, A. I., Mayfield, J. A., Lorenz, M., Rodgers, K. R., DuBois, J. L., and Lukat-Rodgers, G. S. (2018) Distinguishing active site characteristics of chlorite dismutases with their cyanide complexes. Biochemistry 57, 1501-1516. 
(49) Geeraerts, Z., Rodgers, K. R., DuBois, J. L., and Lukat-Rodgers, G. S. (2017) Active Sites of O2-Evolving Chlorite Dismutases Probed by Halides and Hydroxides and New Iron-Ligand Vibrational Correlations. Biochemistry 56, 4509-4524.

(50) Schaffner, I., Mlynek, G., Flego, N., Pühringer, D., LibisellerEgger, J., Coates, L., Hofbauer, S., Bellei, M., Furtmüller, P. G., Battistuzzi, G., Smulevich, G., Djinovic-Carugo, K., and Obinger, C. (2017) Molecular Mechanism of Enzymatic Chlorite Detoxification: Insights from Structural and Kinetic Studies. ACS Catal. 7, 79627976.

(51) Hofbauer, S., Gruber, C., Pirker, K. F., Sündermann, A., Schaffner, I., Jakopitsch, C., Oostenbrink, C., Furtmüller, P. G., and Obinger, C. (2014) Transiently produced hypochlorite is responsible for the irreversible inhibition of chlorite dismutase. Biochemistry 53, $3145-3157$. 